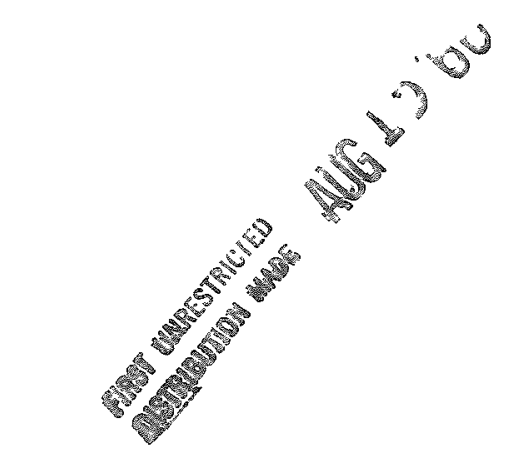

路, 8.00 .50

RL - SEP -823

UC -4, Chemistry

(TID 4500 , 46th Ed.)

THERMAL STABILITY OF NITRATE FORM ANION RESINS
IN A VENTED SYSTEM

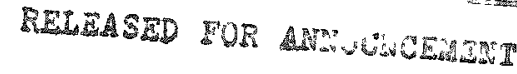

IN MCHAR SCIENCE ABSTRACTS

\title{
THERMAL STABILITY OF NITRATE FORM
IN A VENTED SYSTEM
}

By

II. T. Fu11 am

Plutonium Chemistry Laboratory

Research and Engineering Operation

Chemical Processing Department

December, 1965

\section{HANFORD ATOMIC PRODUCTS OPERATION \\ RTCHLAND, WASHINGTON}

Work performed under Contract No. AT (34-1)-1350 between the Atomic Energy Commission and General Electric Company

\section{Printed by/for the U. S. Atomic Energy Commission}

'rinted in USA. Price \$2.00. Available from the clearinghouse for Federal Scientific and Technical Information, National Bureau of Standards, U. S. Department of Commerce, Springfield, Virginia

\section{LEGAL NOTICE}

This report was prepared as an account of Governgant sponsored work. Netther the United States, nor the Cummssion, nor any gerson aetng on behalf of the Commisgton:

A. Makes any warranty or representatum, expreseed or mplied, with respect to the accuract, pompleteness, or usefulness of the unformation contained in this report, or that the use of any information, apparatus, nethot, or process disclobed in this report may not bniringe of any information, agpas

privately owmed rights; or
B. Assumes any liablities with respect to the use of, or for damages resulting from the

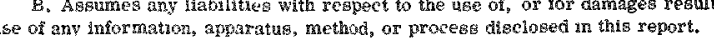

As used in the above, "gernon acting on behalf of the Commission" inciudes any empiusee or contractor of the Commusenon, or employec of such eontrator, to the extent that

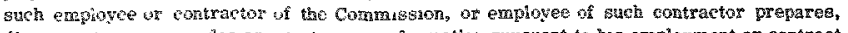
dissemanates, or provides aecese to, any unformation nursuant $w$ his exployment or contrast with the commen or or has emplogment with such eontraetor. 


\section{DISCLAIMER}

This report was prepared as an account of work sponsored by an agency of the United States Government. Neither the United States Government nor any agency Thereof, nor any of their employees, makes any warranty, express or implied, or assumes any legal liability or responsibility for the accuracy, completeness, or usefulness of any information, apparatus, product, or process disclosed, or represents that its use would not infringe privately owned rights. Reference herein to any specific commercial product, process, or service by trade name, trademark, manufacturer, or otherwise does not necessarily constitute or imply its endorsement, recommendation, or favoring by the United States Government or any agency thereof. The views and opinions of authors expressed herein do not necessarily state or reflect those of the United States Government or any agency thereof. 


\section{DISCLAIMER}

Portions of this document may be illegible in electronic image products. Images are produced from the best available original document. 
TABLE OF CONTENTS

I. INTRODUCTION . . . . . . . . . . . . 1

II. SUMMARY AND CONCLUSIONS. . . . . . . . . . . 1

III. THERMAL IGNITION OF ANION RESINS

A. Resin Structure........... 3

B. Resin Ignition ........... 4

C. Determination of Ignition Temperature

1. Experimental Procedure ........ 5

2. Variables Affecting Ignition Temperature . 7

a. Heating Rate . . . . . . . . . . 8

b. Anion Resin Form . . . . . . . . 9

c. Resin Brand............... 10

d. Cross-Linkage。. . . . . . . . . . 11

e. Loading. . . . . . . . . . . . . 13

f. Resin Volume ............. 16

g. Aging. . . . . . . . . . . . . . 19

h. Miscellaneous Factors......... 19

D. Calorimetric Studies . . . . . . . 20

IV. DISCUSSION

A. Theoretical Treatment........... 24

B. Extrapolation of Experimental Data . . . . . 29

C. Recommended Operating Practices....... . 29

V. REFERENCES . . . . . . . . . . . 30

VI. ACKNOWLEDGMENT ............... 31

VII。 APPENDIX A .............. 33

VIII。APPENDIX B . ............ 36 
THERMAL STABILITY OF NITRATE FORM ANION RESINS

IN A VENTED SYSTEM

I. INTRODUCTION

The use of anion exchange resins in the purification of plutonium was initiated as a production operation at Hanford in 1956. The process was used at Hanford and other sites for several years without incident. Beginning in 1962, however, a series of incidents occurred at various locations which raised serious doubt as to the inherent safety of the process. Following a fire in the ion exchange purification section of the Redox Plant in November, 1963, (1) a program was undertaken at Hanford to reevaluate the safety of using anion resins in actinide processing employing nitric acid.

As part of this program, Van Slyke, Jansen, and Swift (2) have studied the heat effects and resin stability in closed nitric acid-resin systems on an engineering scale (i.e., 4 in. dia columns). This report will cover studies on the thermal stability of anion resins in a vented system. Most of the work reported herein was on a laboratory scale involving small volumes of resin $(<10 \mathrm{mI})$

II。 SUMMARY AND CONCLUSIONS

When a nitrate form anion exchange resin is heated above a certain critical temperature, in an open system, a thermal excursion will result The temperature at which the thermal excursion is initiated is called the self-ignition temperature,

The experimental results obtained in this work show that the absolute value of the self-ignition temperature for anion resins will depend on a number of factors: 
- Resin form - With unloaded anion resins, only the nitrate form showed self-ignition tendencies. The chloride, sulfate, and hydroxide forms simply charred on heating.

- Heating rate - More rapid heating leads to a lower ignition temperature.

- Resin brand - Thermal stability varies greatly from brand to brand.

- Cross-1inkage - Increased cross-1inkage gives a lower ignition temperature.

- Loading - When an anion resin is loaded with a nitratecontaining complex [ie, $\mathrm{Pu}\left(\mathrm{NO}_{3}\right)_{6}=, \mathrm{Th}\left(\mathrm{NO}_{3}\right)_{6}{ }^{=}$], the ignition temperature decreases as the loading level is increased.

- Resin volume - Increasing the significant geometrical dimension of the containment vesse1 lowers the ignition temperature.

- Aging - Used resin shows a higher ignition temperature than fresh resin.

- Pre-treatment - The treatment given the resin prior to measuring the ignition temperature will affect the results obtained. For example, if the resin is washed with nitric acid prior to testing, the ignition temperature will depend on the normality of the acid used. The higher the acid normality, the lower the ignition temperature.

The lowest ignition temperature measured was $135^{\circ} \mathrm{C}$, which occurred with resin heavily loaded with plutonium. The volume of resin used in this test was limited to about $1 \mathrm{cc}$. Larger volumes of plutonium-loaded resins (which were not tested) would undoubtedly give lower ignition temperatures.

Even though the ignition temperature determinations were carried out under carefully-controlled conditions, the spread of data obtained for a given resin sample was much greater than expected. This probably indicates that at least one other 
variable, not considered, affected the results obtained.

III. THERMAL IGNITION OF ANION RESINS

A. Resin Structure

The anion resins studied in this work were of the strongly basic type. Dowex 1 and IRA 401 are polystyrene-divinyl benzene polymers, with the active group being a quaternary ammonium group. The resin structure is shown below for the chloride form of the resin.

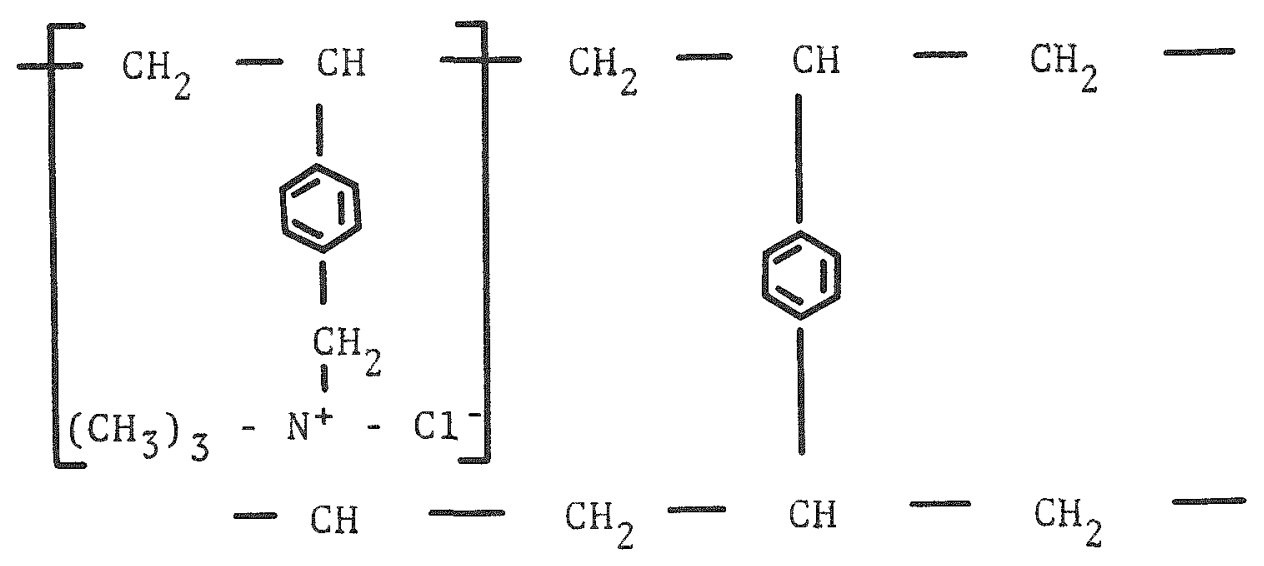

The resin is normally obtained from the manufacturer as the chloride form and converted to the nitrate form by the user. Conversion is accomplished by washing the resin with dilute $\mathrm{HNO}_{3}$ until all traces of chloride ion are removed.

$$
\mathrm{R}^{+} \cdot \mathrm{Cl}^{-}+\mathrm{NO}_{3}{ }^{-} \rightarrow \mathrm{R}^{+} \cdot \mathrm{NO}_{3}^{-}+\mathrm{Cl}^{-}
$$

The other resin tested in this work was Permutit SK. Its exact structure is unknown, but it is probably also a polystyrene-divinyl benzene polymer, with a pyridinetype active group associated with the polymer. 
B. Resin Ignition

When the nitrate form of an anion resin, such as Dowex 1 , is heated in an open system to an elevated temperature, self-ignition of the resin occurs and a thermal excursion results. This occurs even when the resin is heated in an inert atmosphere. When polystyrene or polystrene cross-linked with divinyl benzene is heated in a similar manner, thermal degradation of the polymer occurs without self-ignition. (3) This indicates that the thermal explosion obtained with nitrate-form anion resins is due to the presence of nitrate containing active groups on the resin.

A typical heating curve for nitrated resin is shown in Figure 1 and was obtained by slowing heating the resin in an open vessel in an oil bath. As can be seen from the plot, the resin temperature follows that of the bath until the bath temperature approaches $80^{\circ} \mathrm{C}$. At this point the evaporation of moisture from the resin becomes appreciable and resin temperature lags behind the bath temperature. When evaporation of the liquid phase is complete, the resin temperature increases rapidly and again approaches the bath temperature. Continued in * crease of the bath temperature results in an increased rate of resin degradation, and a point is reached at which the resin temperature will exceed the bath temperature because of internal heating. When the heat generation rate becomes greater than the rate at which heat can be transferred to the bath, the resin temperature increases exponentially. The reaction rate increases in a similar fashion, and a thermal excursion results. The temperature at which this thermal excursion occurs is taken as the ignition temperature for the resin (see Figure 1)。 


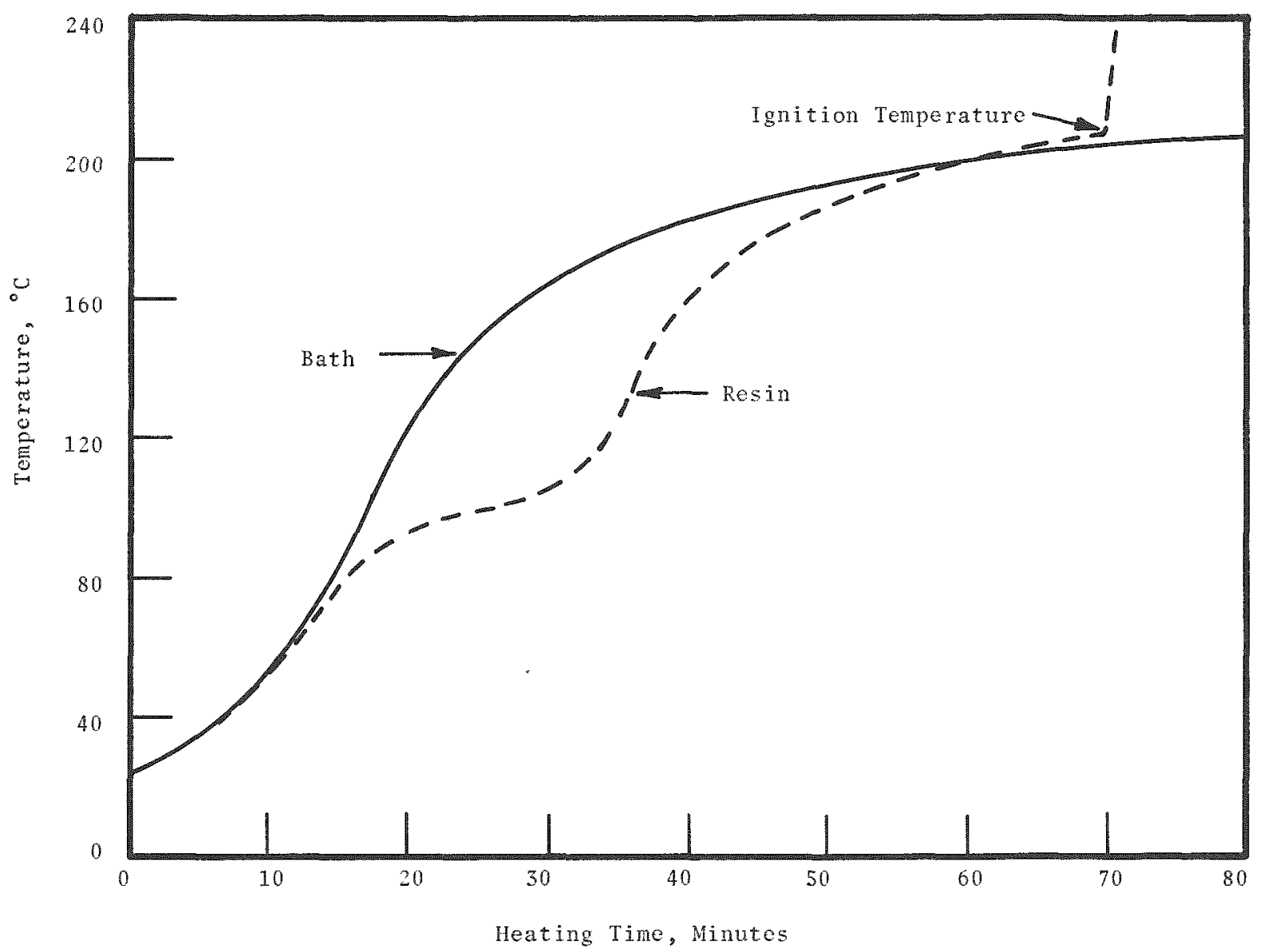

FIGURE 1. Typical Heating Curve

C. Determination of Resin Ignition Temperatures

1. Experimental Procedure

The self-ignition temperatures of anion resins were measured by use of the equipment shown in Figure 2. The resin to be tested, after being drained of excess liquid, was placed in a small glass vial which was then placed in an oil bath. The bath was heated with a hot plate until resin ignition occurred. The temperatures of the resin and oil bath were followed with either thermocouples or thermometers. The heating curves obtained were similar 


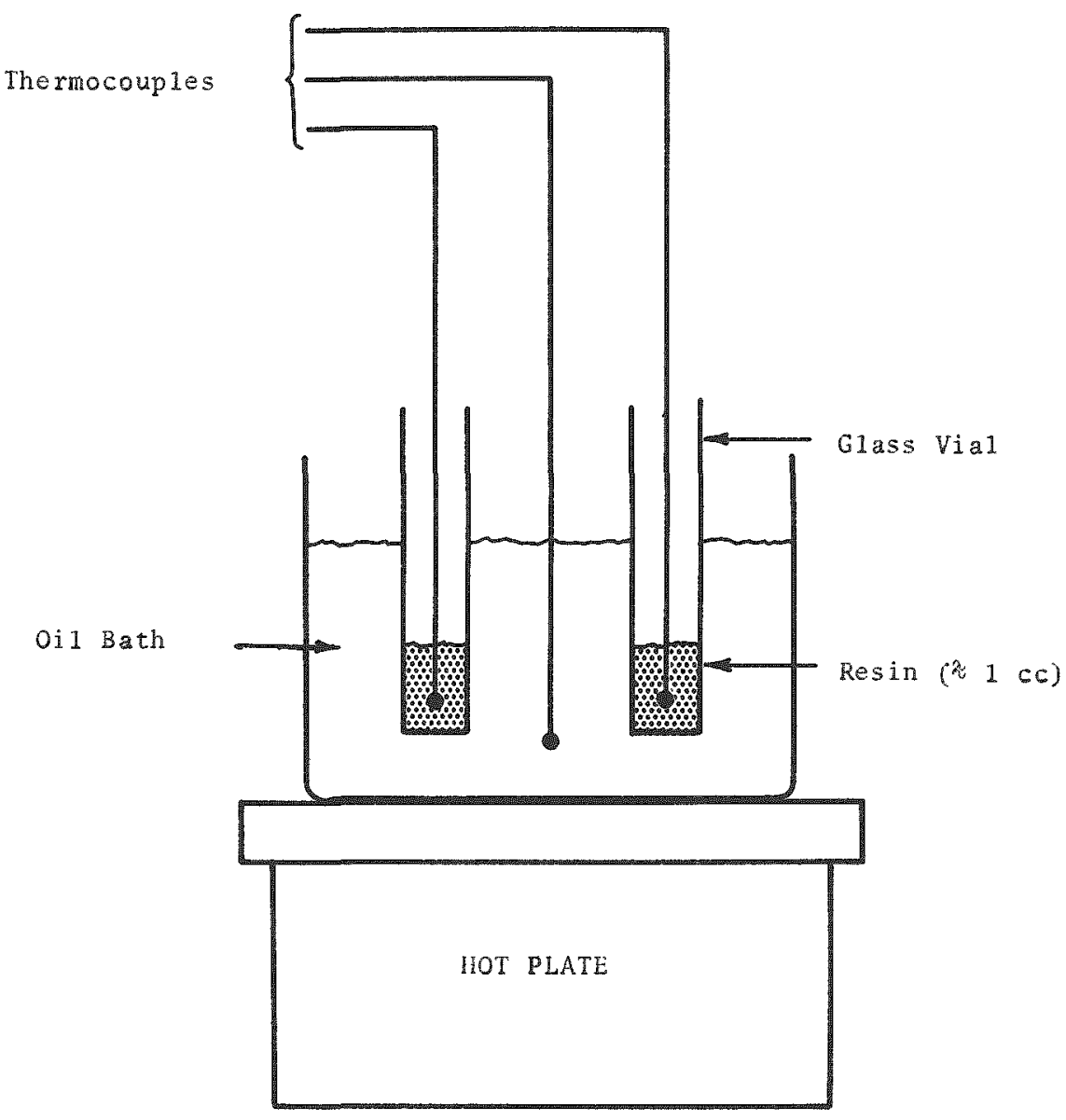

\section{FIGURE 2. Equipment for Ignition Temperature Studies}

to the ones shown in Figure 1.

The glass vials used to contain the resin, had a diameter of approximately 0.5 in. Between 1 and $2 \mathrm{~m} 1$ of resin were used in each test, which gave a bed depth of 1 to $1.5 \mathrm{~cm}$. The small volumes of resin were used, because early work showed that with plutonium-loaded resins combustible gases were evolved upon resin ignition, which could cause a serious fire if present in sufficient quantity.

The thermocouple used to follow resin temperature gives a certain point temperature $T_{R}$ for the 
resin bed. Since the temperature is not uniform throughout the bed, it is possible for certain areas of the bed to be higher than $\mathrm{T}_{\mathrm{R}}$. This is especially true if heating has been very rapid and the wall temperature $\mathrm{T}_{W}(\approx$ bath temperature) is substantially greater than $T_{R}$. Then the beads in direct contact with the wall are

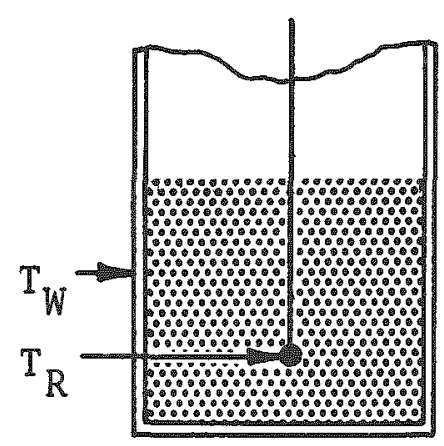
hotter than $\mathrm{T}_{\mathrm{R}}$, and even as the ignition temperature of these beads is approached, heat is still transferred from the wall to the thermocouple location. At ignition of the beads adjacent to the wal1, the measured resin temperature is below the wall temperature and gives an abnormally low ignition temperature. It is essential, therefore, to heat the resin relatively slowly in the region where ignition is expected, so that $T_{R}$ is close to, or in excess of, the bath temperature when ignition occurs.

For a given resin specimen, the measured ignition temperature varied from determination to determination even though the experimental conditions were held as constant as possible. In some cases the spread of data was as great as $15{ }^{\circ} \mathrm{C}$. For this reason, at least 10 determinations were made for each case, and the ignition temperature was taken as the arithmetic average of the individual temperature measurements. In most cases, two or more test samples were run concurrently in the bath to obtain more data points.

\section{Variables Affecting Ignition Temperature}

Soon after the ignition experiments were begun, 
it became apparent that a number of variables were influencing the results obtained. The effect of these variables on ignition temperature was studied, and experimental results are discussed in detail below.

\section{a. Heating Rate}

The effect of heating rate on ignition temperature was measured for two samples of nitrate-form Permutit $S K$ resin. One sample was simply nitrate form resin which had been washed with water and then drained of the excess liquid. The second sample was similar except the resin was vacuum-dried to reduce the moisture content below $10 \%$ prior to heating (Figure 3 ). With the drained resin, a tremendous spread in the data was obtained; and the only conclusion drawn is that the ignition temperature does increase with reduced heating rate. When testing the predried resin, the ignition temperature varied linearly with heating rate, but only three heating rates were tested.

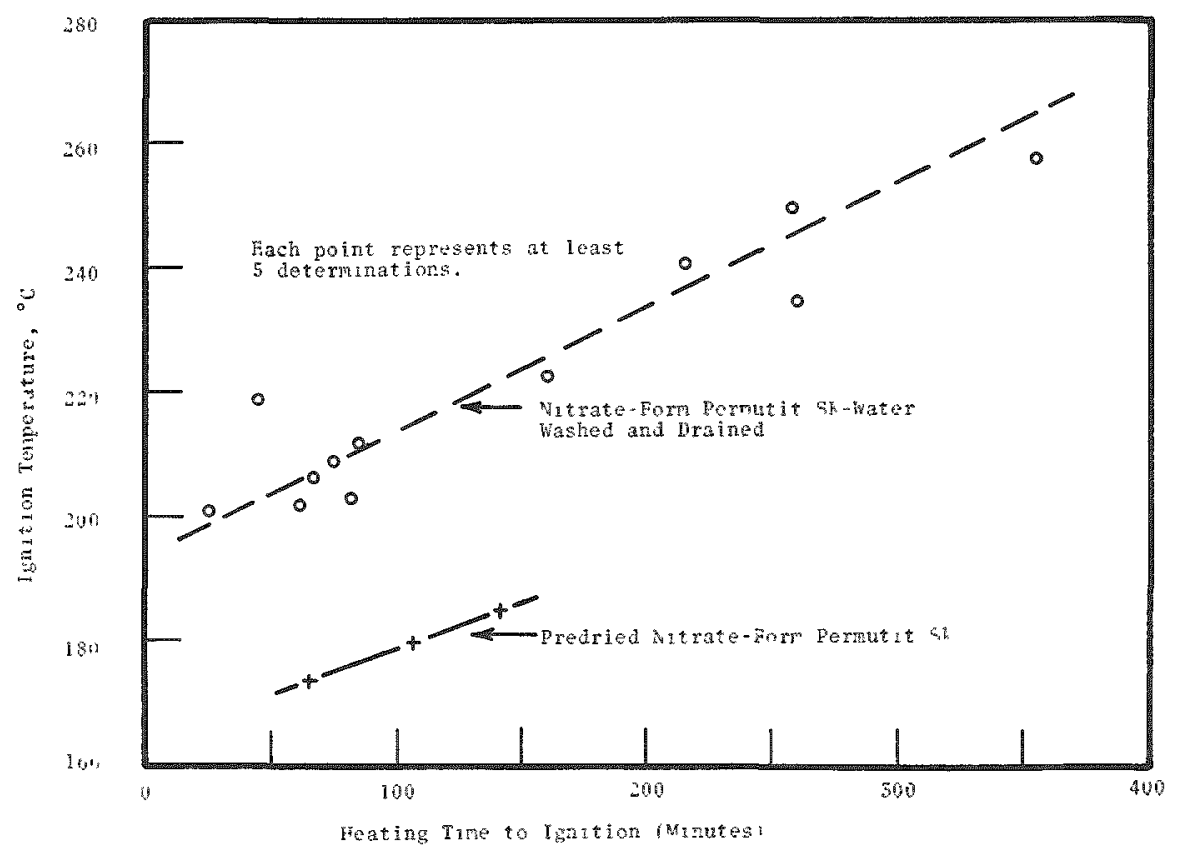

FIGURE 3. Ignition Temperature as a Eunction of Heating Rate 


\section{b. Anion Resin Form}

Of all the anion exchange resins tested, only the nitrate form of the unloaded resins ignited spontaneously when heated. The chloride, sulfate, and hydroxide forms did not ignite even upon prolonged heating at $300^{\circ} \mathrm{C}$. The resin beads did char; but no exothermic reactions, abnormal temperature rises, or excessive gassing were ever detected. Visual observation indicates the charring begins about $180^{\circ}$ and ends at about $300{ }^{\circ} \mathrm{C}$, with the beads being completely black in color. The beads, although undergoing discoloration, retain their spherical shape.

Resin partially converted to the nitrate form will ignite spontaneously upon heating. Tests indicate that at least $25 \%$ of the active sites have to be in the nitrate form for ignition to take place.

Loading the anion resin with nitrate containing groups such as $\mathrm{Pu}\left(\mathrm{NO}_{3}\right)_{6}=, \mathrm{Th}\left(\mathrm{NO}_{3}\right)_{6}=\mathrm{Ce}\left(\mathrm{NO}_{3}\right)_{6}=$, or reactive groups such as dichromate $\left(\mathrm{Cr}_{2} \mathrm{O}_{7}{ }^{2}\right.$ ) also causes the resin to ignite on heating.

Cation resin (ie, Dowex 50w) does not ignite up to $300{ }^{\circ} \mathrm{C}$, but simply chars, as do the non-nitrate forms of anion resins.

The results of the various tests are summarized in Table I.

TABLE I. Ignition Temperature $\left({ }^{\circ} \mathrm{C}\right)$ for Various Forms of Resin

\begin{tabular}{|c|c|c|c|c|c|c|}
\hline$\underline{\operatorname{Resin}}^{(a)}$ & $\mathrm{NO}_{3}^{-}$ & $\mathrm{Cl}^{-}$ & $\mathrm{OH}^{-}$ & $\mathrm{SO}_{4}=$ & $\begin{array}{l}5: \mathrm{NO}_{3}{ }^{-} \\
5 \\
\mathrm{OHI}\end{array}$ & $\begin{array}{ll}50 \% & \mathrm{NO}_{3} \\
50 \% \mathrm{OH}^{-}\end{array}$ \\
\hline Permutit SK & $\overline{212}$ & $\bar{N} \cdot \overline{I .}(b)$ & N.I. & $\overline{\text { N.I. }}$ & - & - \\
\hline Dowex $1-X_{4}$ & 274 & N.I. & - & N.I. & - & - \\
\hline IRA 401 & 204 & N.I. & N.I. & N.I. & 268 & 265 \\
\hline
\end{tabular}

(a) Each test lot of resin was given the same pretreatment consisting of washing the resin thoroughly with distilled water, draining, and air drying for several hours at room temperature.

(b) X.I.--did not ignite upon heating to $300^{\circ} \mathrm{C}$ 


\section{c. Resin Brand}

Three brands of resin, Permutit SK, IRA 401, and Dowex 1-X4, were tested during this phase of the work. All three are thought to be strongly basic polystyrenedivinyl benzene resins having approximately $4 \%$ crosslinkage. The Dowex $1-\mathrm{X} 4$ and IRA 401 have quaternary ammonium groups at the active sites; whereas the exact structure of permutit SK is not known, but appears to involve pyridine groups.

The ignition temperature of the three resins are shown in Figure 4. In carrying out these tests, the nitrate-form resins were washed with nitric acid of various concentrations; the ignition temperature was then determined as described earlier. As can be seen, wash acid normality affects the ignition temperature very markedly.

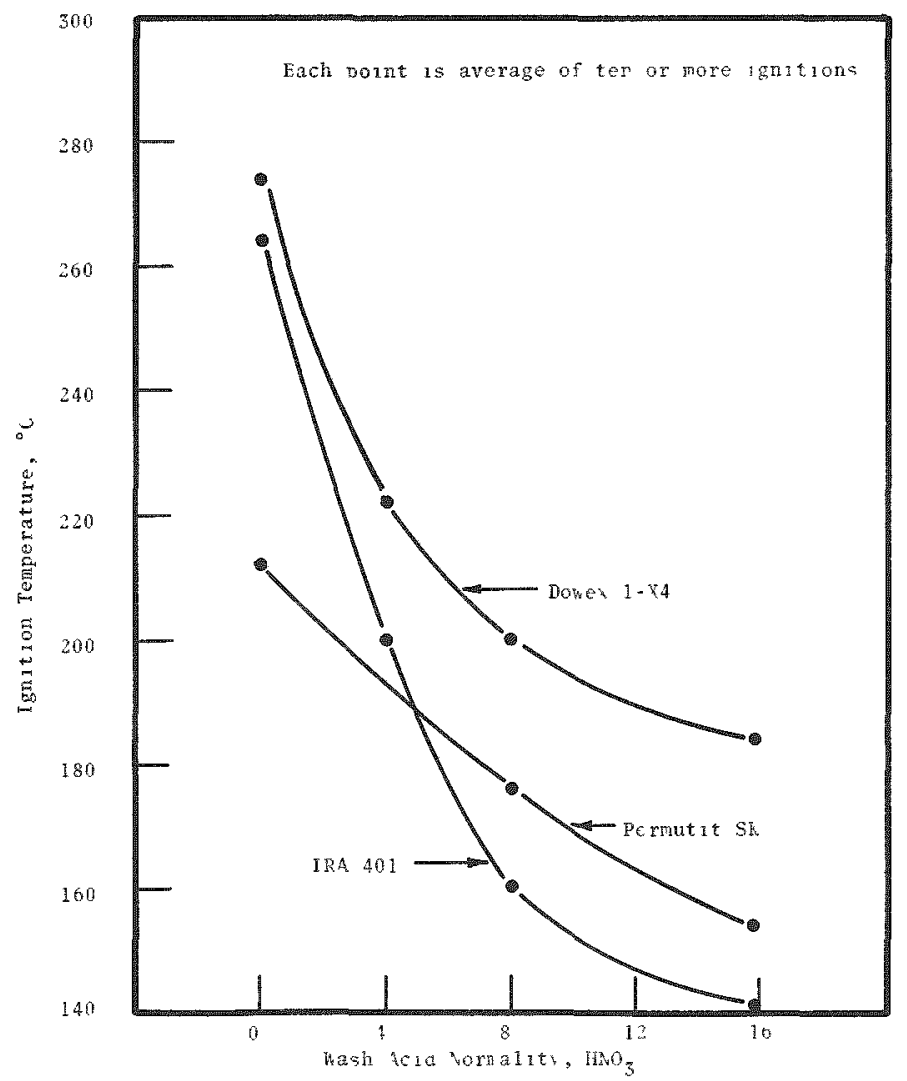

FIGURE 4. Ignition Temperature vs. Wash Acid Normality for Various Brands of Resin 
Dowex 1-X4 shows the greatest thermal stability throughout the entire acid concentration range. IRA 401 stability approaches that of Dowex $1-X 4$ at $10 \mathrm{w}$ concentrations, but falls off very rapidly at higher concentrations. Permutit SK shows the least stability variation with acid concentration and falls in between Dowex I-X4 and IRA 401 at high acid concentrations.

The reasons for the variation of ignition temperature with the wash acid concentration are unknown at this time, but one theory ${ }^{(4)}$ is that as the nitric acid concentration is increased, a complex is formed in increasing amounts due to hydrogen bonding, which increases the nitrate concentration of the resin.

$$
\mathrm{R}^{+} \cdot \mathrm{NO}_{3}^{-}+\mathrm{HNO}_{3} \rightarrow \mathrm{R}^{+} \cdot \mathrm{H}^{-}\left(\mathrm{NO}_{3}\right)_{2}^{-}
$$

This increase in nitrate concentration increases the reaction rate, and as a result, the ignition temperature is lowered (see section IV.A).

\section{d. Cross-Linkage}

The ignition temperature of polystyrene divinyl benzene resins decreases as the divinyl benzene content of the resin is increased. This is shown in Figure 5, where the ignition temperatures of Dowex 1 resins having crossinkages varying from 1 to $10 \%$ are plotted versus wash acid normality. Again, the pronounced effect of the acid concentration on ignition temperature can be seen. In Figure 6, the data are cross-plotted to show more clearly the effect of cross-1inkage. The data show that the ignition temperature decrease is almost linear with respect to increasing divinyl benzene content of the resin. A change from 1 to $10 \%$ cross-1inkago decreases ignition temperature about $50^{\circ} \mathrm{C}$. 


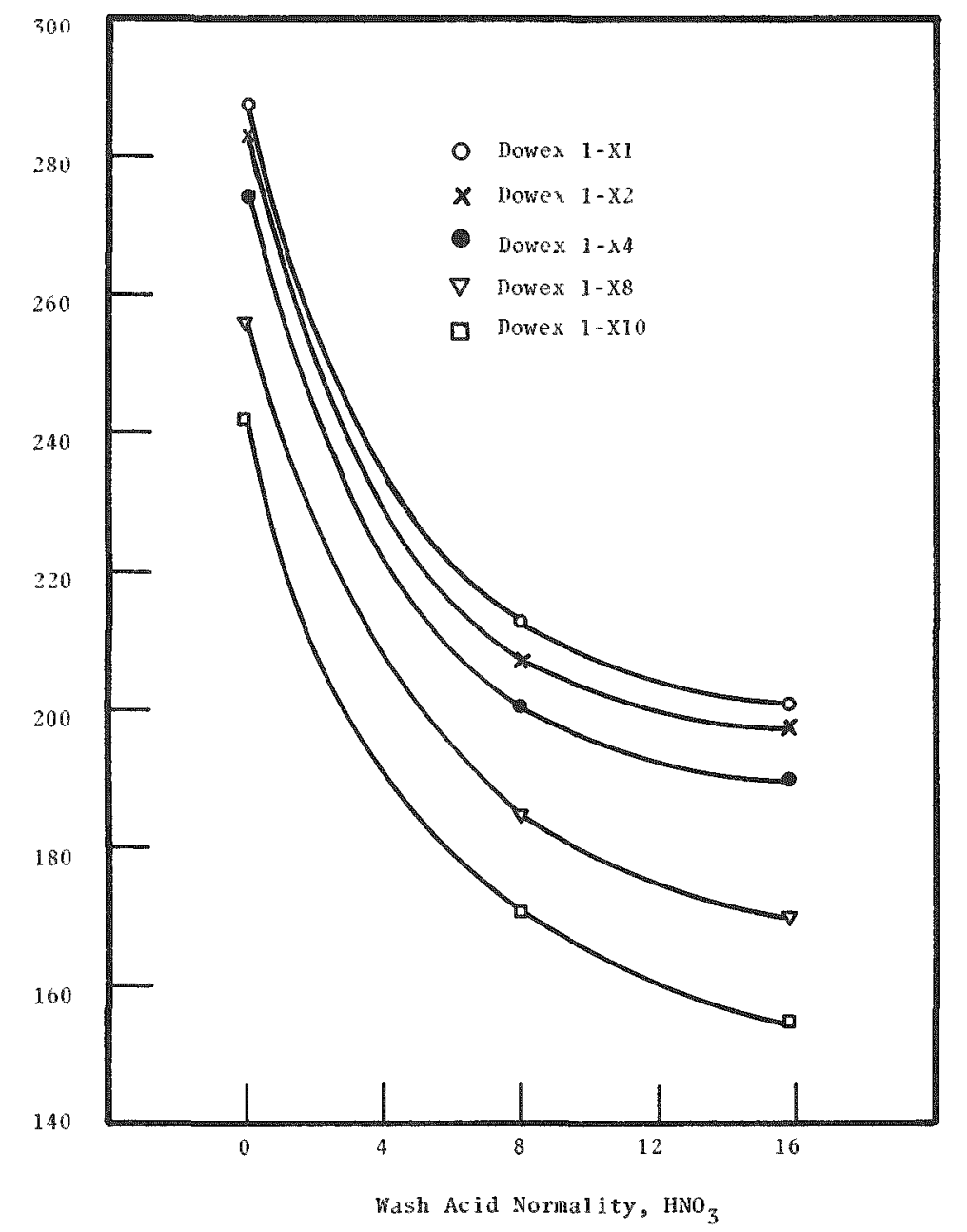

FIGURE 5. Effect of CrossLinkage on Ignition Temperature

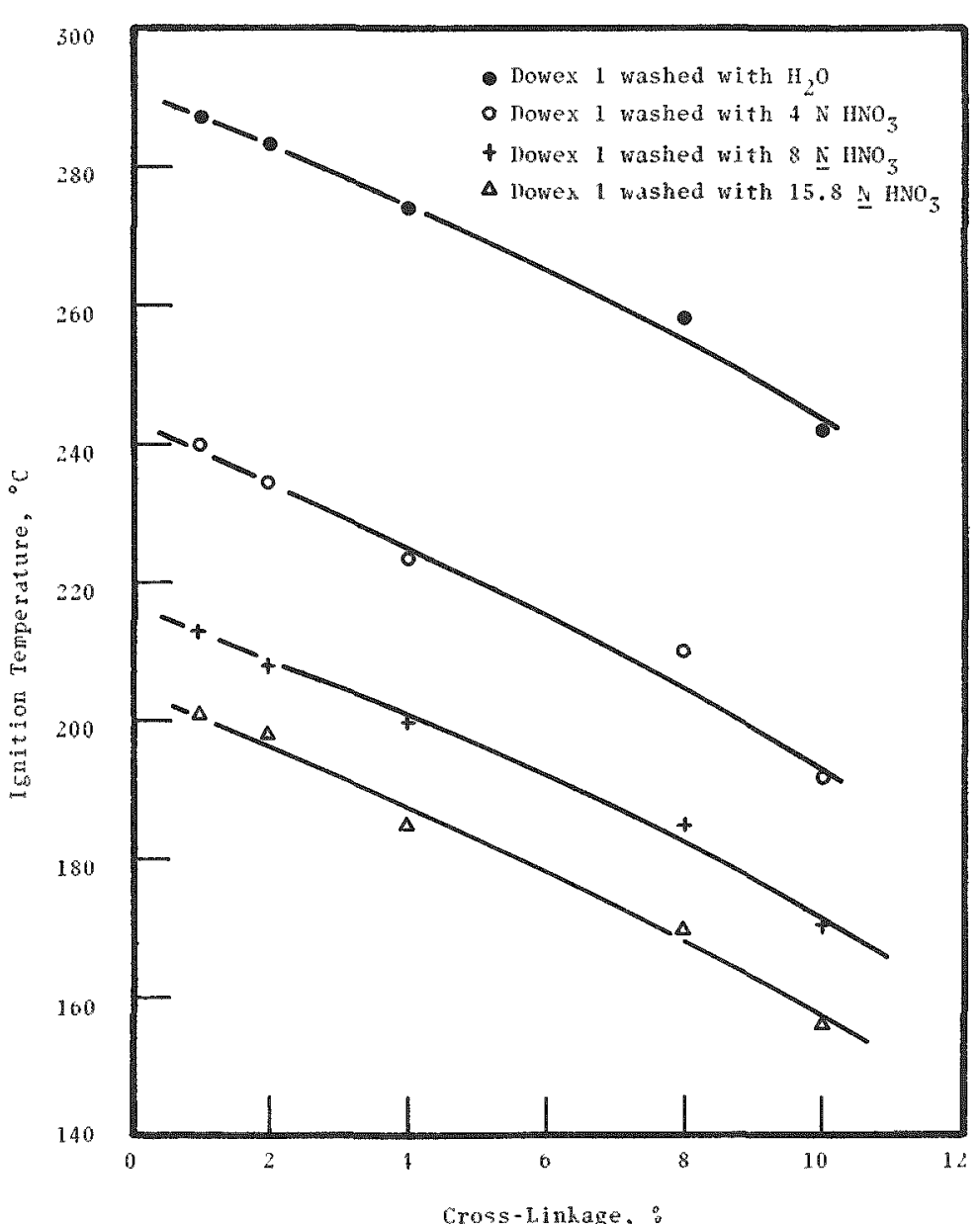

$\stackrel{\sim}{N}$

FIGURE 6. Ignition Temperature as a Function of Cross-Linkage 


\section{c. Loading}

Resin loading (depending on the species loaded) has a very marked effect on ignition temperature. Nitrate containing complexes such as the hexanitrato complexes of plutonium, cerium, and thorium lower the ignition temperature drastically. Other species such as dichromate ions lower the temperature, but not to the same extent as the nitrato complexes. This is shown by the data in Figure 7 , where the ignition temperature for Permutit SK resin is plotted as a function of plutonium loading.

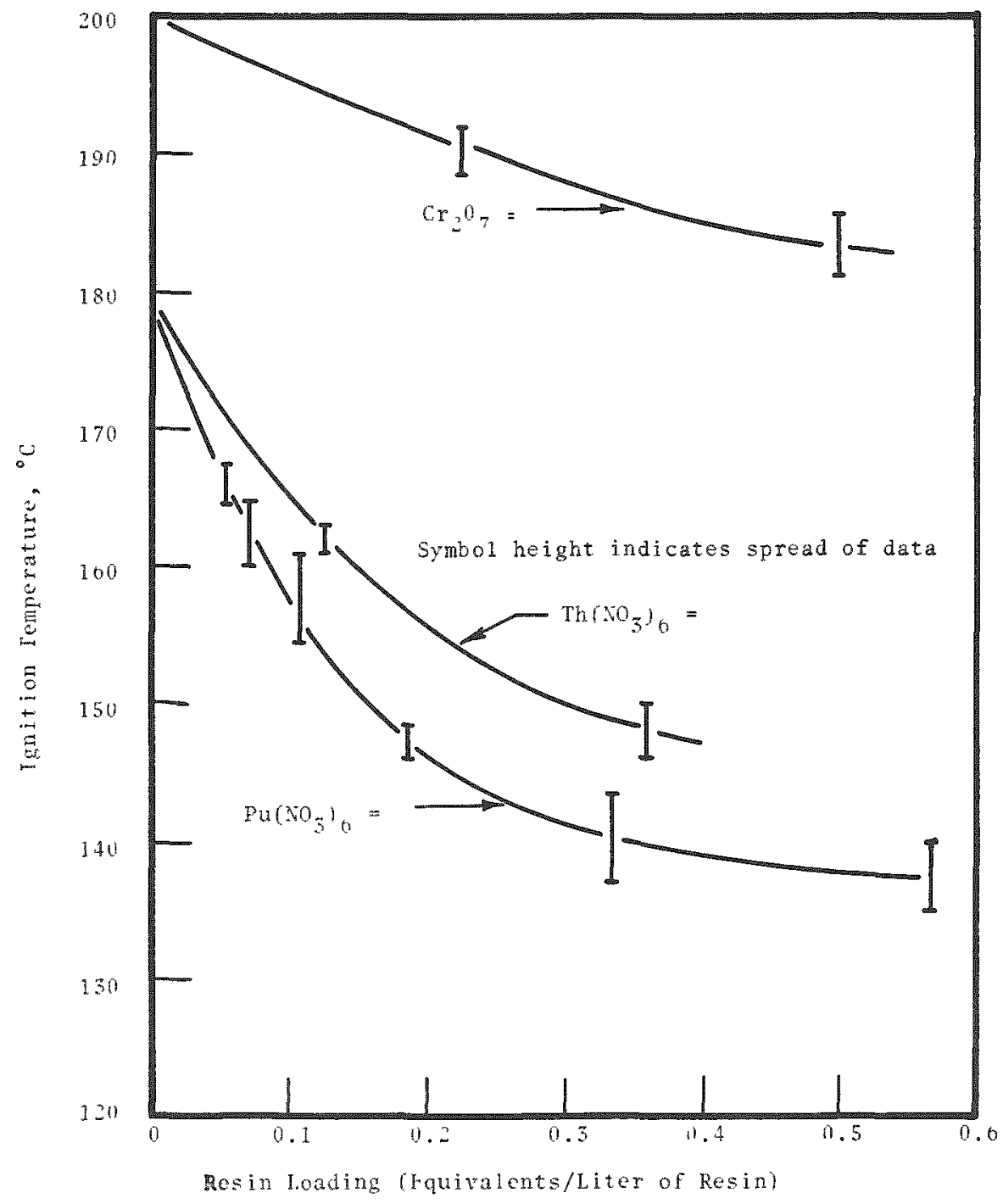

FIGURE 2. Ignition Temperature as a Function of Resin Loading 
When plutonium is loaded on an anion resin, it loads as the hexa-nitrato complex:

$$
2\left[\mathrm{R}^{+} \cdot \mathrm{NO}_{3}{ }^{-}\right]+\mathrm{Pu}\left(\mathrm{NO}_{3}\right)_{6}{ }^{-2} \gtrless 2 \mathrm{R}^{+} \cdot \mathrm{Pu}\left(\mathrm{NO}_{3}\right)_{6}{ }^{-2}+2 \mathrm{NO}_{3}{ }^{-}
$$

When the resin is fully loaded, the nitrate concentration of the resin is three times as high as in the unloaded form. This increase in nitrate concentration increases the heat generation rate; and as a result, the ignition temperature is lowered.

One very marked difference is apparent when plutoniumloaded resin is heated to ignition as compared to unloaded nitrate-form resin. With unloaded resin, the reaction upon ignition proceeds relatively slowly, and a dense, white smoke evolves from the resin vessel. It normally takes about 0.5 to $1.0 \mathrm{sec}$ for all of the resin in the container ( $\approx I \mathrm{CC}$ ) to react. All of the resin beads stay in the vessel during the reaction They retain their spherical shape, but appear to be completely carbonized.

With plutonium-loaded resin, a much more vigorous and rapid reaction is obtained. Upon ignition, glowing resin beads are expelled from the container and are completely consumed by oxidation. The only solid residue appears to be plutonium dioxide Visible gas evolution is much less; the dense, white fumes, so evident upon ignition of unloaded resin, are much less noticeable. In addition, a much greater heat evolution results upon ignition of the plutonium loaded resin. The photographs in Figure 8 show the visible differences between the two reactions.

The gases evolved upon ignition of plutonlum-loaded resins are combustible, as evidenced during one ignition test when a fire ball formed above the ignition vessel 
and burned for about $30 \mathrm{sec}$ until it was extinguished. The combustibles probably result from thermal pyrolysis of the resin. Pyrolysis of the unloaded resin should also occur upon ignition, but attempts to ignite the gases evolved from the resin were unsuccessful.

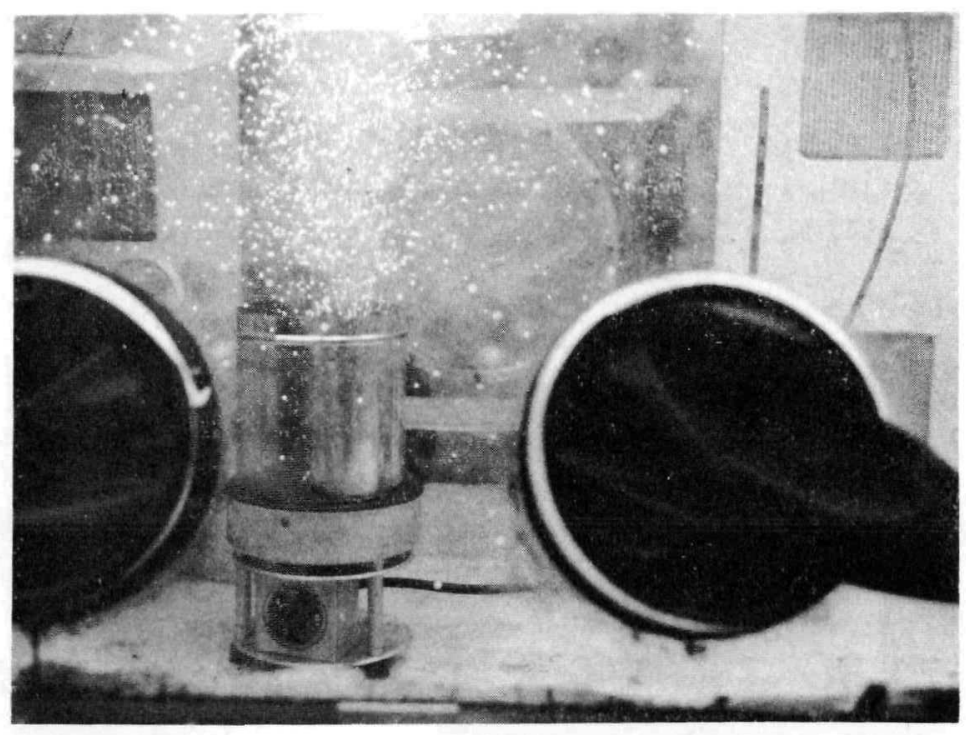

8-A. Ignition of $\mathrm{Pu}$-Loaded Resin

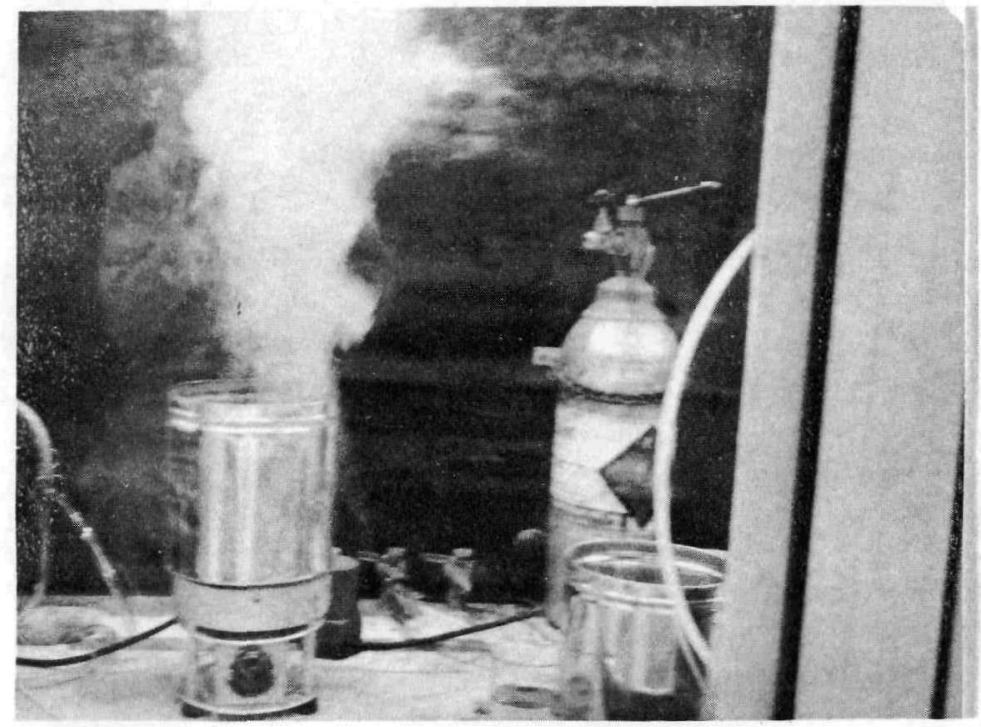

8-B. Ignition of Nitrated Resin

FIGURE 8. Resin Ignition 
Dichromate loaded resin reacts in essentially the same manner as unloaded resin, except the evolution of white fumes is appreciably less.

When the resin is loaded with an ion such as pertechnatate, it no longer ignites upon heating, but simply chars--as does the chloride- or hydroxide-form resin.

f. Resin Volume

In attempting to measure the effect of resin volume on ignition temperature, it was found that the experimental procedure, described in section III, could not be used for volumes larger than about $50 \mathrm{~m} 1$. This was due to the poor thermal conductivity of the drained resin. When heating a large volume of resin, the low thermal conductivity made it almost impossible to keep the bath temperature and the temperature in the center of the resin bed close together unless the heating rate was very slow; in which case ignition did not occur, and the resin simply charred. When faster heating rates were used, the resin would ignite at the wall of the vessel, and the volume effect was essentially negated.

The procedure finally developed is shown in Figure 9. The resin was placed in a spherical vessel having top and bottom openings. The bottom opening was plugged with glass wool to support the resin bed. Thermocouples were placed at the bottom of the plug, at its top, at the side wall of the vessel, and near the center and top of resin bed. Air or inert gas was heated in an external coil, passed up through the resin bed, and exited through the top outlet of the vessel. The entire system was insulated with Fiberfrax and a foamed silica insulation. 


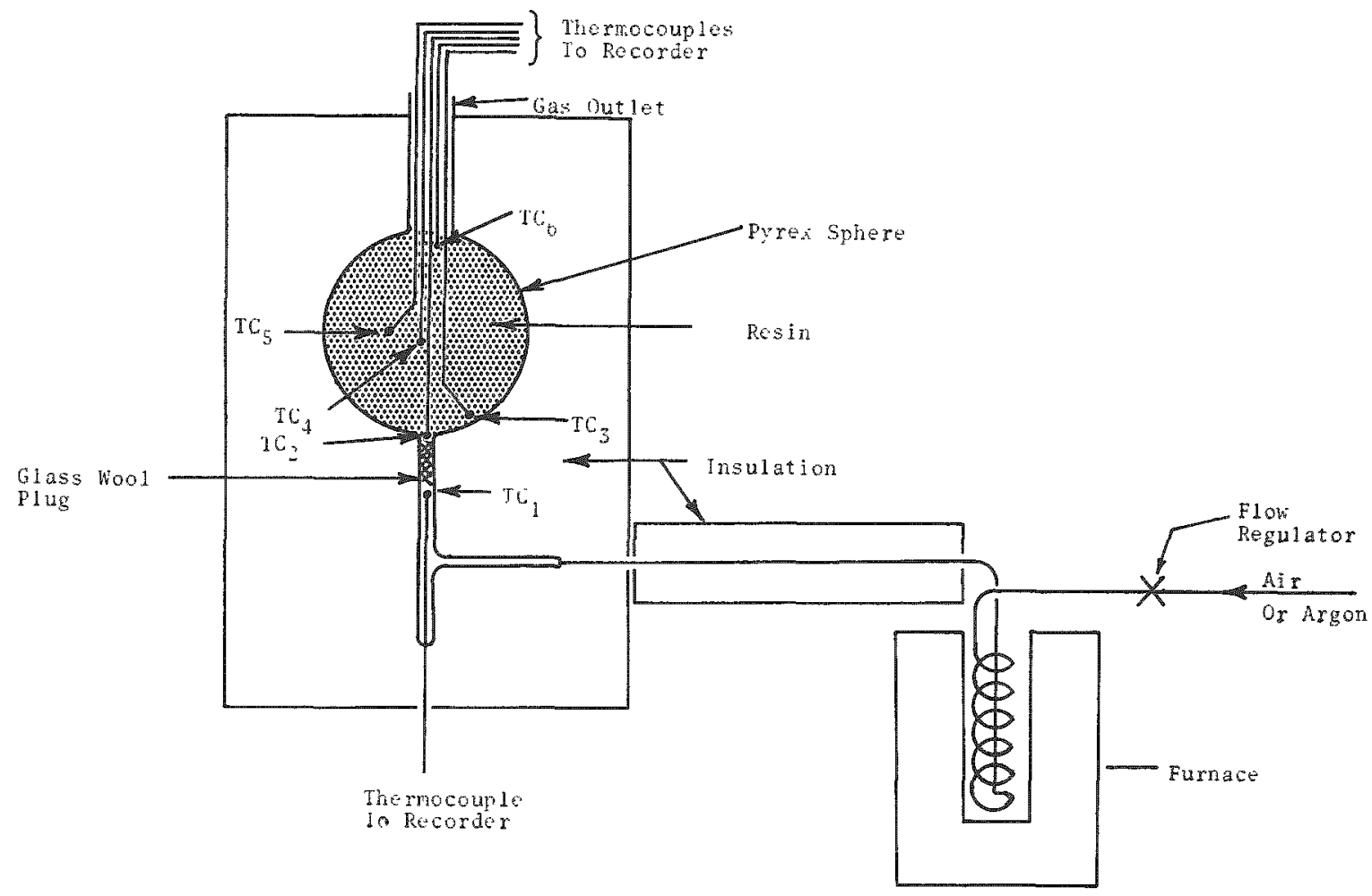

FIGURE 9. Equipment for Measuring Ignition Temperature for Large Volumes of Resin

In measuring the ignition temperature, the resin was placed in the vessel and the cold gas flow was started at a set rate. The gas temperature was slowly increased until ignition occurred. A typical heating curve for the system is shown in Figure 10. As can be seen, the temperature across the sphere at any one time is far from uniform.

The ignition temperature was measured for waterwashed nitrate form Permutit $\mathrm{SK}$ resin in spherical vessels having volumes of $100,200,500$, and $1000 \mathrm{ml}$ (Figure 11). The volume effect shows up. 


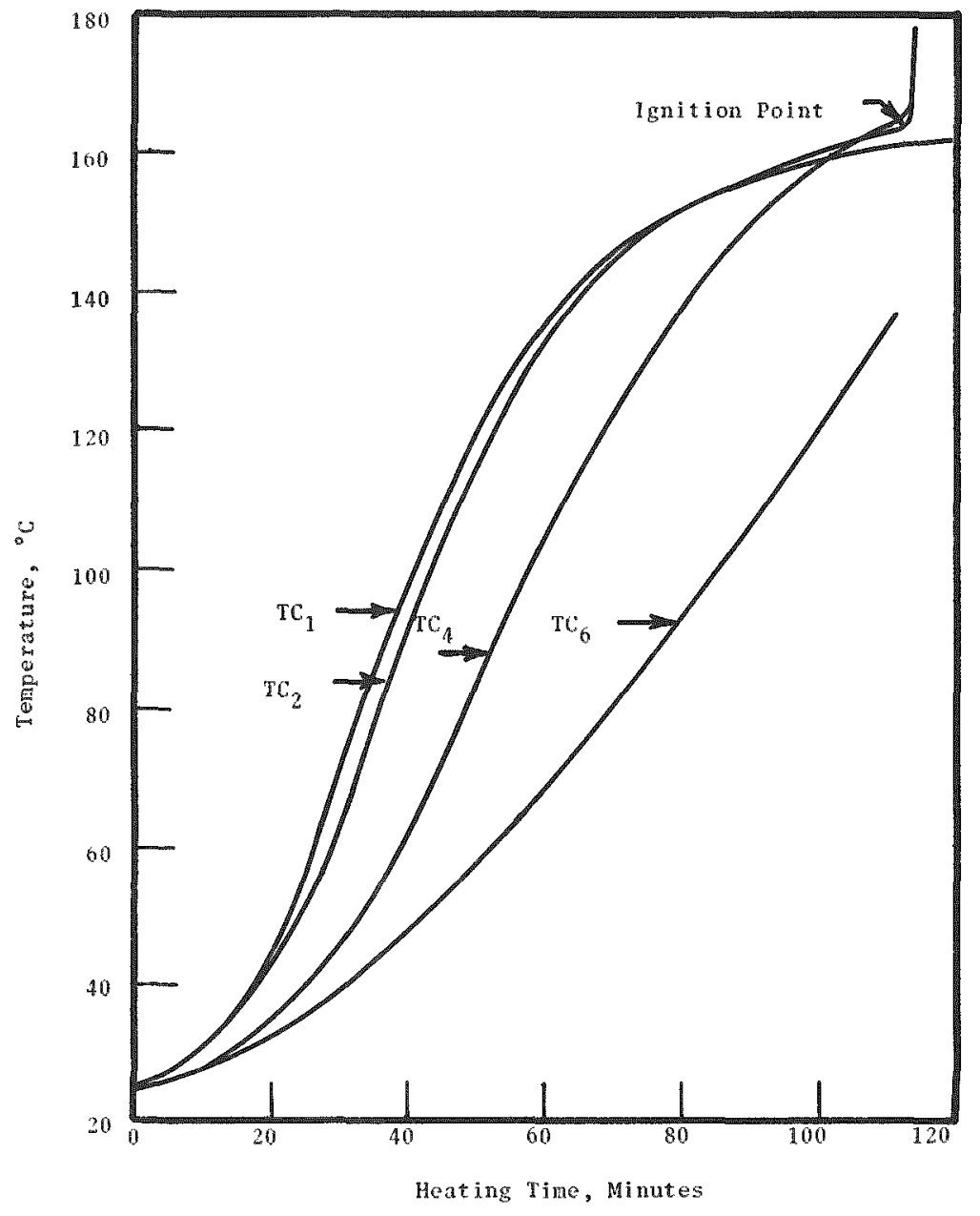

FIGURE 10. Typical Heating Curve, Large Vessels

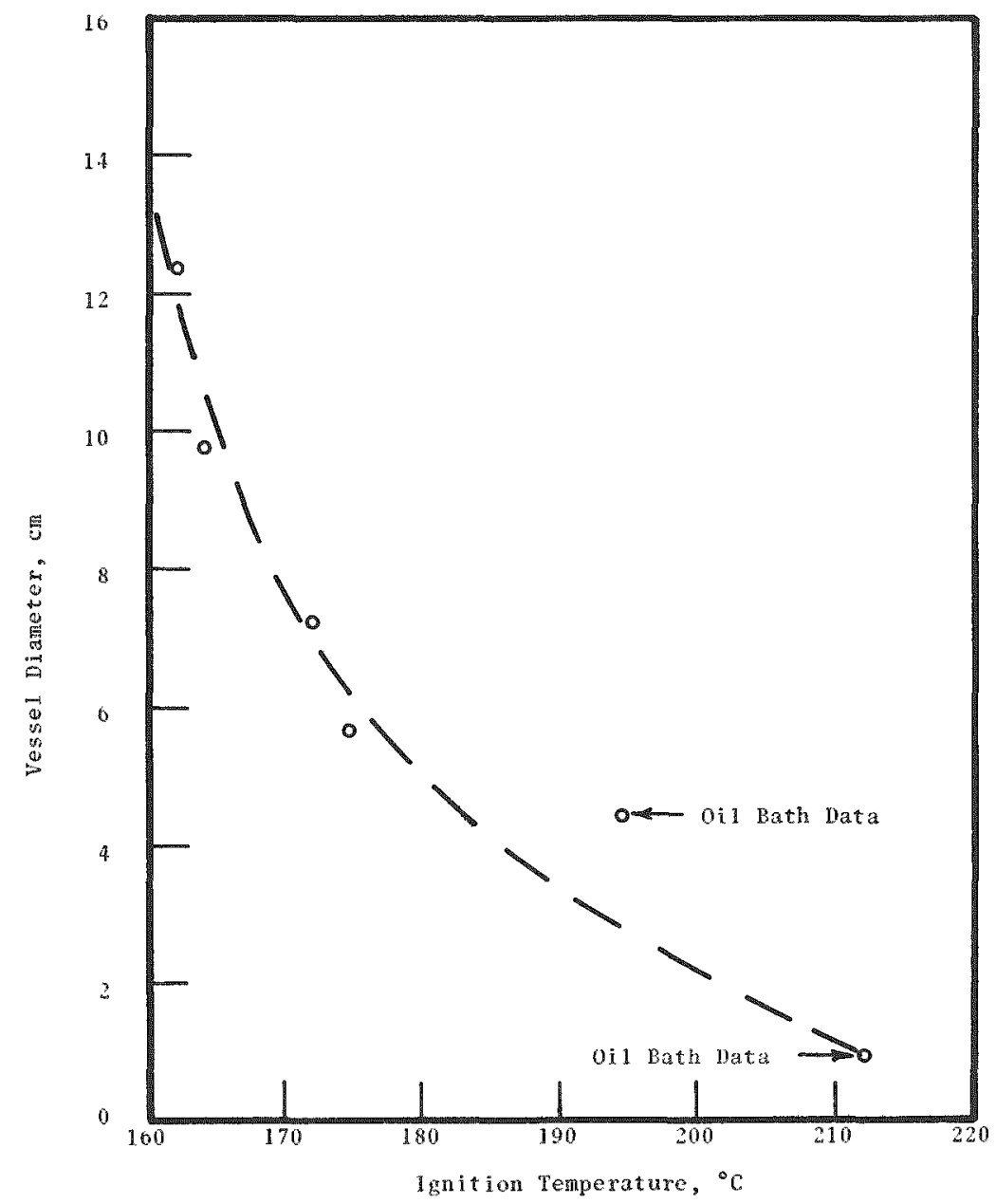

FIGURE 11. Ignition Temperature as a Function of Vessel Volume 


\section{g. Aging}

Several samples of used resin (contaminated, but with no measurable plutonium content) were obtained from production operations for testing. These resins had been used in plutonium service, but their overall history was not well known. Tests indicated that the ignition temperature of used resin is higher than that of unused resin. This is to be expected, since some resin degradation does occur during use. This resin degradation would decrease the reactant concentration of the resin being ignited and, in turn, raise the ignition temperature.

\section{h. Miscellaneous Factors}

Other factors appear to affect the ignition temperature of the resins, but only qualitative information was obtained. For some reason yet unexplained, the initial moisture content of the resin affects its ignition temperature. If the resin is vacuum-dried at low temperature $\left(\approx 40\right.$ to $\left.50^{\circ} \mathrm{C}\right)$, the ignition temperature appears to be lowered while resin dried at higher temperature $\left(90\right.$ to $100^{\circ} \mathrm{C}$ ) raises the ignition temperature. The latter effect is easy to understand since some degradation will occur during the high temperature drying which uses up reactants, but the effect of low-temperature drying cannot be explained.

Allowing loaded resin to stand in nitric acid or in the cold loading solutions for long periods of time appeared to affect the ignition temperature of the resin. The results, however, did not appear to be reproducible. In some cases, dichromate-loaded resin, after standing for several days, ignited at temperatures only slightly above the freshly-loaded resin, while some did not ignite at al1 
The particle size of the resin beads does not appear to affect ignition temperature. Four mesh sizes 20 to 50,50 to 100,100 to 200 , and 200 to 400 - of the same initial moisture content were tested, and the variation in ignition temperature between the various size ranges was within the experimental error of the test procedure.

D. Calorimetric Studies

The work of Van Slyke, Jansen, and Swift (2) has shown that the critical temperature for a sealed 4 in. dia resin column containing $7 \mathrm{~N} \mathrm{HNO}_{3}$ is slightly above $100{ }^{\circ} \mathrm{C}$. The critical temperature for larger columns is even lower. Therefore, it was felt that given a column operating at 70 to $80^{\circ} \mathrm{C}$, a loading reaction might generate enough heat to raise the column to the critical temperature. To test this possibility, the heats of loading for two loading reactions were measured in an adiabatic calorimeter.

$$
\begin{aligned}
& 2\left[\mathrm{R}^{+} \cdot \mathrm{NO}_{3}^{-}\right]+\mathrm{Pu}\left(\mathrm{NO}_{3}\right)_{6}=2 \mathrm{R}^{+} \cdot \mathrm{Pu}\left(\mathrm{NO}_{3}\right)_{6}=+2 \mathrm{NO}_{3}{ }^{-} \\
& 2\left[\mathrm{R}^{+} \cdot \mathrm{NO}_{3}^{-}\right]+\mathrm{Cr}_{2} \mathrm{O}_{7}=2 \mathrm{R}^{+} \cdot \mathrm{Cr}_{2} \mathrm{O}_{7}=+2 \mathrm{NO}_{3}{ }^{-}
\end{aligned}
$$

Dichromate loading was studied because dichromate ion was found on resin in the Redox ion exchange column following the fire. (1) The calorimeter used for these measurements is shown in Figure 12 . The procedure used was to fill the Dewar with a known volume of loading solution, insert the resin bulb (containing a weighted amount of resin) into the Dewar, and bring the system to thermal equilibrium with stirring; the temperature was measured with a differential thermometer which could be read to $0.001{ }^{\circ} \mathrm{C}$. When equilibrium was reached, the bulb was broken, and the temperature change for a given period 
of time determined. Since the heat capacity of the calorimeter is known, the heat of loading can be calculated by analyzing the resin for the extent of loading.

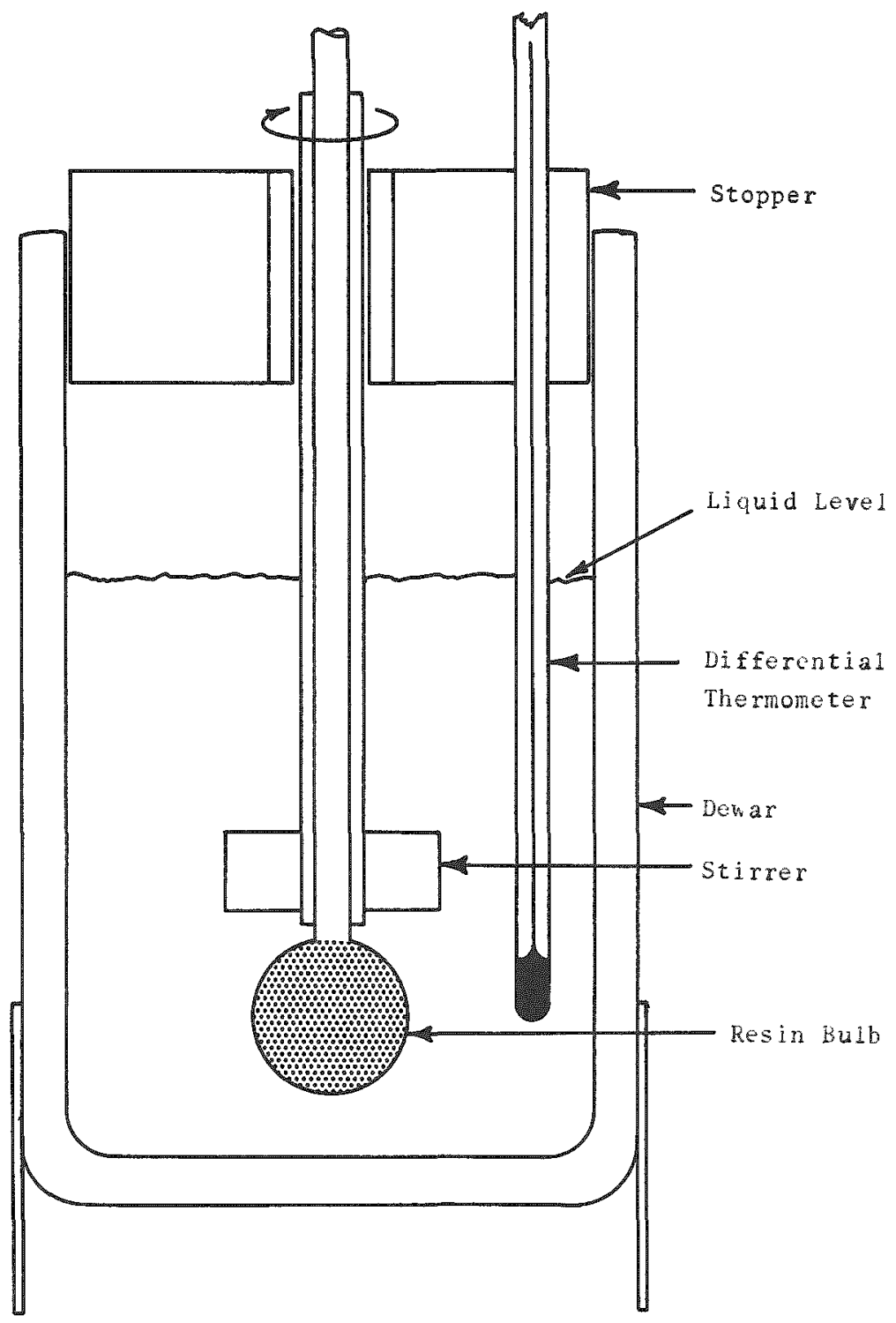

FIGURE 12. Adiabatic CaZorimeter

The heat of loading for the dichromate loading reaction was found to be $-10.2 \pm 0.2 \mathrm{kcal} / \mathrm{g} \mathrm{mole} \mathrm{of} \mathrm{Cr}_{2} \mathrm{O}_{7}=$ loaded. It was found, however, that the rate of loading for dichromate ion (even at elevated temperatures) is 
low. Therefore, the heat generation rate per unit time from the loading reaction is quite low, even though the heat evaluation per mole of loaded $\mathrm{Cr}_{2} \mathrm{O}_{7}=$ is large. For the dichromate loading reaction to give a dangerous temperature increase for a static bed, the resin column would have to be very well insulated.

The heat of loading of plutonium was measured and found to be $-9.8 \pm 1.0 \mathrm{kcal} / \mathrm{g}$ atom of plutonium loaded.

The heat evolved when the resin degrades in the absence of air was measured by using a twin calorimeter (Figure 13) and the procedure developed by Borchardt and Daniels. (5) When this equipment is used, the two cells of the calorimeter are filled with equal volumes of mineral oil of known heat capacity. A weighed amount of

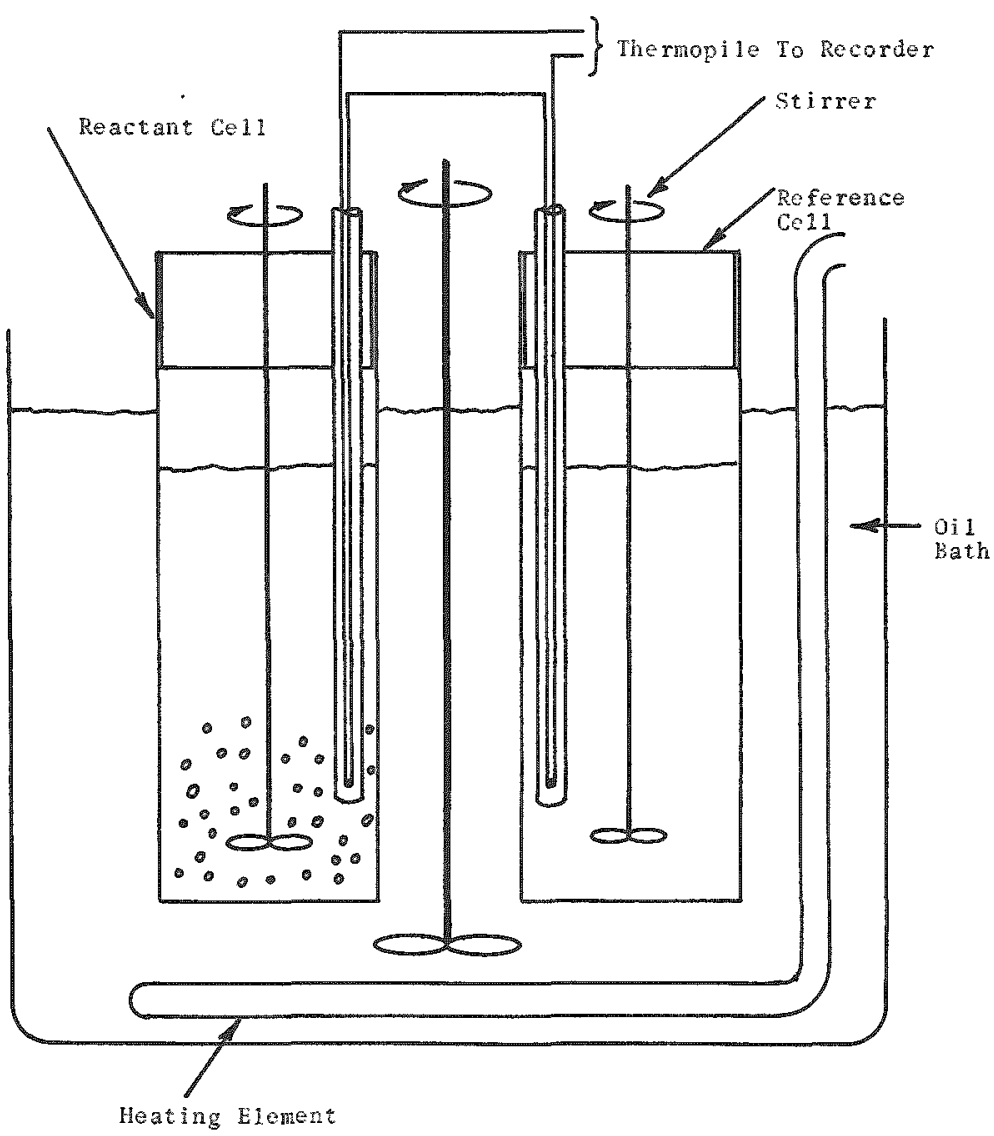

FIGURE 13. Twin Calorimeter 
resin ( $\approx 5 \mathrm{~g}$ ) is added to one cell and the stirrers are turned on. The oil bath is heated, and the temperature difference between the two cells measured with a 20 couple thermopile and recorded on a 0 to $1 \mathrm{mV}$ recorder. The heat of reaction was obtained by using the technique of Borchardt and Daniels.(5)

By use of Permutit $\mathrm{SK}$ resin in the nitrate form, which had been water-washed and air-dried to a moisture content of $<1 \%$, a heat of reaction of $210 \pm 50$ calories per gram of dry resin was obtained.

The heats of combustion of Dowex 1 and Permutit SK resin were measured in an oxygen bomb calorimeter. The results obtained are tabulated below.

$\underline{\text { Resin }}$

Permutit SK

Dowex 1-X1

Dowex $1-X_{2}$

Dowex $1-X_{4}$

Dowex $1-\mathrm{X} 8$

Dowex $1-\mathrm{X} 10$

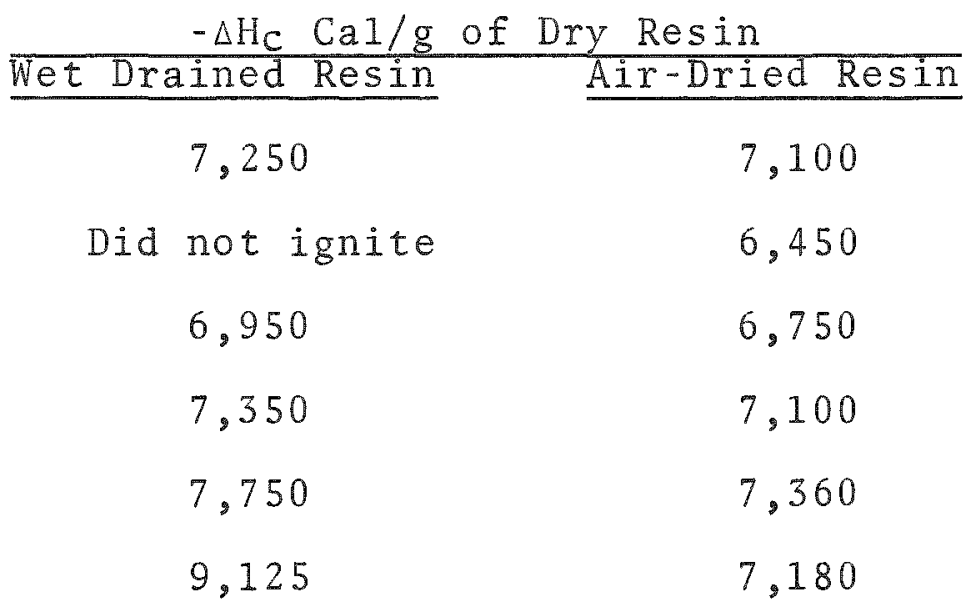

As expected, the heat of combustion varies with crosslinkage of the resin for Dowex 1. However, the variation of heat of combustion (on a dry basis) with the moisture content is difficult to explain and was not expected. It is possible that variations in moisture content of the drained resin, from the analyzed value due to evaporation during handing prior to weighing, could account for the higher heat of combustion of the wet resin. 
IV: DISCUSSION

A. Theoretical Treatment

Theoretical analyses of the reaction system (described above) can be made by utilizing the thermal ignition theories developed by Semenov (6) and Frank-Kamenetskii. (7) For an isolated system undergoing an exothermic chemical reaction, thermal stability of the system is obtained when the rate of heat generation within the system is equal to the heat loss from the system to the surroundings. If the rate of heat loss is less than the heat generation rate, thermal stability is impossible; the temperature of the reacting system will increase exponentially and a thermal explosion results.

If one assumes that the nitrate form anion resin degrades by a single reaction, the rate of heat generation for the resin system will be given by the equation

(1) $Q_{R}=f(c) \cdot H_{R} \cdot V \cdot Z \cdot e^{-E / R T} R$

where $f(c)$ is the concentration dependence of the reaction rate, $H_{R}$ is the molar heat of reaction, $V$ is the system volume, $Z$ is the frequency factor, $E$ is the activate energy, $R$ is the gas constant, and $T_{R}$ is the resin temperature.

The mathematical expression for heat transfer from the system to the surroundings will depend on the geometry of the containment vessel. If heat transfer is by conduction, the heat balance between heat generated by the reaction and that lost by conduction is

(2) $k \nabla^{2} \mathrm{~T}=\mathrm{f}(\mathrm{c}) \cdot \mathrm{H}_{\mathrm{R}} \cdot \mathrm{V} \cdot \mathrm{Z} \cdot \mathrm{e}^{-\mathrm{E} / \mathrm{RT}} \mathrm{R}$

where $k$ is the thermal conductivity of the resin bed and $\nabla^{2}$ is the Laplacian operator. General solutions of this equation for cylindrical and spherical geometries, based on the method of Chambre, lead to the critical vessel wall 
and resin temperatures as a function of the containment vessel's critical dimensions (Appendix A).

Since some heat transfer by convection will occur, the above treatment does not give a completely accurate picture of the resin system, but represents the best evaluation that can be handled reasonably.

A second approach that can be used in the mathematical treatment of the resin systems is to assume that the temperature is uniform throughout the resin bed. This is patently incorrect for a vented system, but a good qualitative description of the system can be obtained by this simplified approach. For this case, the heat exchange between the resin and its containment vessel is given by the equation

$$
\text { (3) } Q_{L}=h S\left(T_{R}-T_{W}\right)
$$

where $S$ is the surface area of the vessel wall, $h$ is the heat transfer coefficient and $T_{W}$ is the wall temperature. Equation (1) is still applicable for the heat generation rate.

At low resin temperature $\left(<100^{\circ} \mathrm{C}\right), \mathrm{Q}_{\mathrm{R}}$ is small and heat will be transferred from the oil bath to the resin, according to Equation (3). At higher temperatures, the $\mathrm{Q}_{R}$ becomes appreciable, and the resin will be heated by both internal heat generation and transfer from the bath. With continued heating, a point will be reached where the resin temperature $\left(T_{R}\right)$ equals the wall temperature $\left(T_{W}\right)$, and the heat transfer rate $\left(Q_{L}\right)$ is zero. A further increase in the resin temperature, due to internal heating, will raise $T_{R}$ above $T_{W}$ and result in a net transfer of heat from the resin to the wall. The resin temperature will continue to increase until $Q_{R}$ equals $Q_{L}$. At this point, as long as the wall temperature is held constant, the system is in thermal 
equilibrium and the system is stable. This is shown in Figure 14, where $Q_{R}$ (curve $A$ ) and $Q_{L}$ (curve $B$ ) are plotted against temperature.

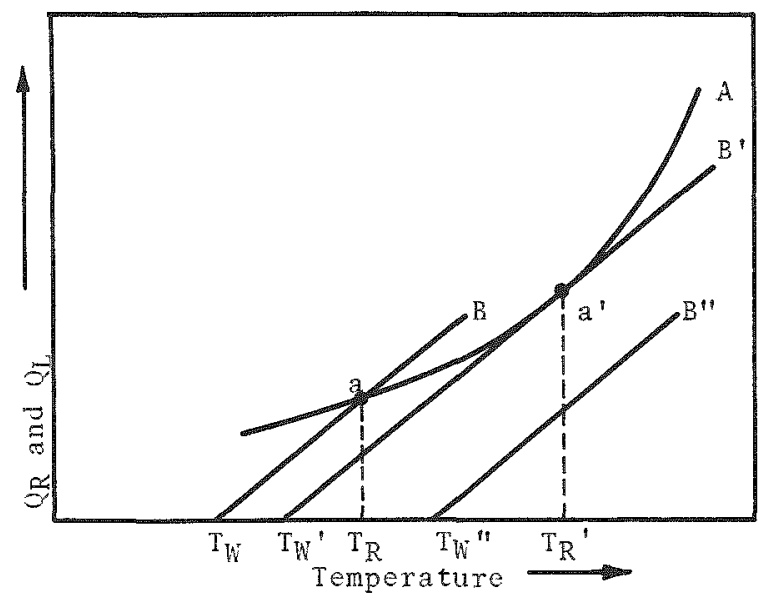

\section{FIGURE 14.}

For a wall temperature $\mathrm{T}_{W}$, the curves intersect at point "a" corresponding to a resin temperature $T_{R}$. This is a stable condition, since for any slight change in the temperature will tend to return the system to $T_{R}$. If the wall temperature is increased to $T_{W}{ }^{\prime}$, the resulting curve $B^{\prime}$ for $Q_{L}$ will be tangent to curve A at point a', corresponding to a resin temperature $T_{R}$ '. The system is again in thermal equilibrium. However, it is not stable because a slight increase in the resin temperature will cause the heating rate to exceed the heat loss and a thermal explosion will result. An increase in wall temperature will have the same effect, since the curve for $Q_{L}$ will no longer intersect that for $Q_{R}$, and the heat production rate will always exceed the cooling rate. The temperature $T_{R}$ ' is the self-ignition temperature for the system, and corresponds to the ignition temperature obtained from the heating curve shown in Figure 1. 
While not rigorously correct, this treatment of the resin system can be used to explain, in a qualitative fashion, the effects which certain variables studied have on the ignition temperature of anion resins.

It was shown experimentally that the rate at which the resin is heated will affect the ignition temperature. As stated previously, the rate of heat generation by the resin decomposition reaction is given by the equation

$$
Q_{R}=f(c) \cdot H_{R} \cdot V \cdot Z \cdot e^{-E / R T_{R}}
$$

where $f(c)$ is the concentration dependence of the reaction rate. In a static nitrate form resin bed, the amount of reactants is limited, and their concentration will decrease as the reaction progresses. This means that the shape of the curve for heat production as a function of temperature will vary depending on the rate at which the resin is heated. With rapid heating, $Q_{R}$ is given by curve A (Figure 15), and the ignition temperature will be $T_{R}$. At a slower heating rate, the curve for $Q_{R}$ is given by $A^{\prime}$, and the ignition temperature is increased to $T_{R}{ }^{\prime}$. At an extremely slow heating rate, all of the reactant would be consumed at relatively low temperature, and self-ignition would never occur.

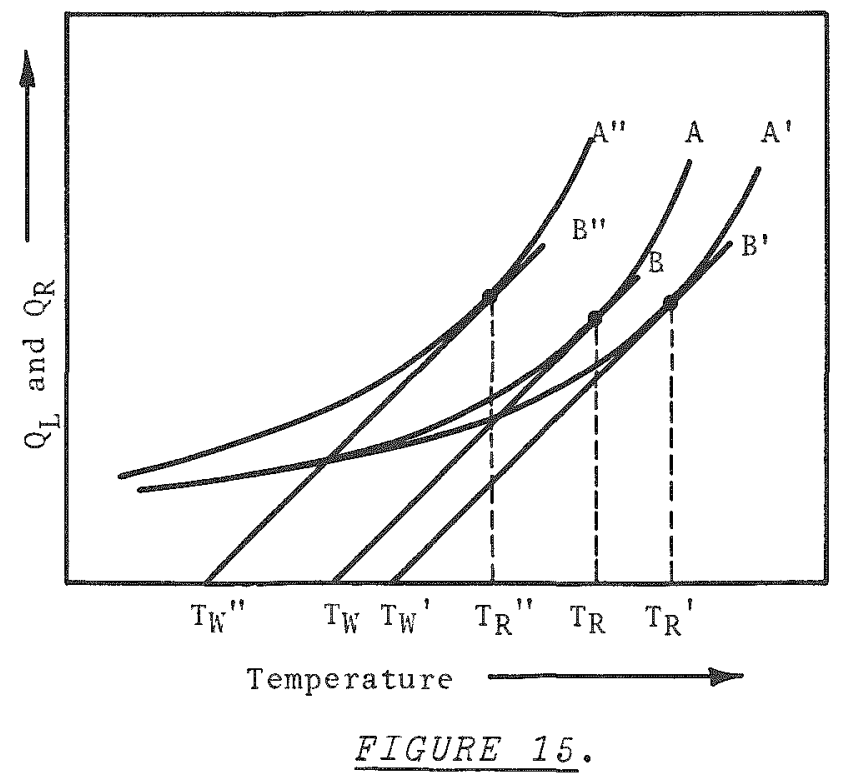


When the initial nitrate concentration of the resin is increased by a loading reaction [ie, $\mathrm{Pu}\left(\mathrm{NO}_{3}\right)_{6}{ }^{=}$], the heat generation rate $Q_{R}$ will be given by curve $A^{\prime \prime}$ (Figure 15): as a result, the ignition temperature will be lowered to $T_{R}{ }^{\prime}$. Therefore, the ignition temperature of plutonium loaded resin decreases on the loading is increased.

Because the volume of a vessel increases more rapidly than its surface area as its critical dimension is increased, the total rate of heat generation $\left(Q_{R}\right)$ will increase more rapidly than the heat loss, $Q_{L}$. This means that the ignition temperature for a given resin should decrease as resin volume increases; such a temperature decrease was confirmed experimentally。

A quantitative evaluation of the effect of resin volume on ignition temperature can be gained by using Equation (2). If the appropriate boundary conditions are applied, Equation (2) can be solved for various vessel geometries and will give the critical wall temperature as a function of the vessel dimensions (see Appendix A). These solutions give the general relationships shown in Figure 16. A second relationship obtained from Equation (2) relates the critical wall temperature $\left(\mathrm{T}_{W}\right)$ to the resin ignition temperature $\left(\mathrm{T}_{R}\right)$ at the center of the vessel by the equation

$$
\text { (4) }{ }^{\theta} \text { crit }=\left(E / R T_{W}{ }^{2}\right)\left(T_{R}-T_{W}\right)
$$

where $\theta_{\text {crit }}$ is a constant depending on vessel shape. For a sphere, ${ }_{\text {crit }}=1.61$; for a cylinder, ${ }_{\text {crit }}=1 \mathrm{n} 4$ 。 If the necessary parameters such as $E, k, f(c)$, and $Z$ are known for a given resin, the relationship between vessel geometry and ignition temperature can then be calculated. 


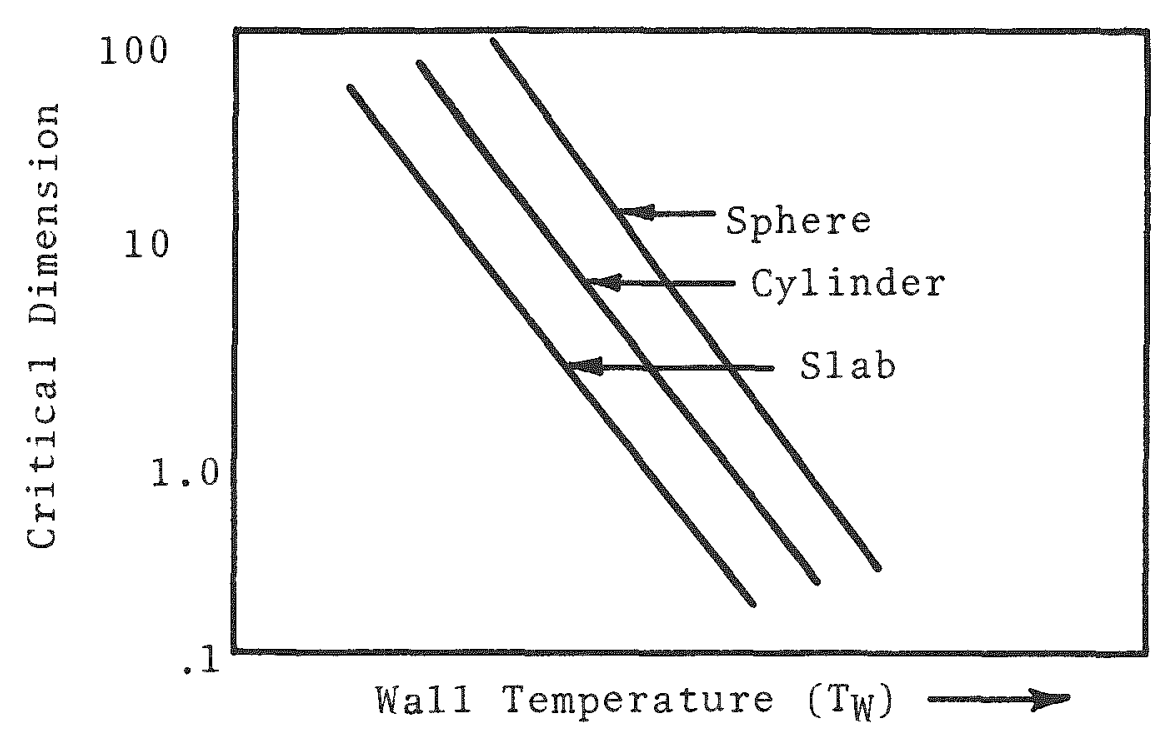

\section{EIGURE 16.}

\section{B. Extrapolation of Experimental Data}

The results indicate that the thermal stability of vented nitrate form anion resin is lower than that previously anticipated, especially when the effect of plutonium loading is considered. The lowest ignition temperature measured was $135{ }^{\circ} \mathrm{C}$, which was obtained with plutonium loaded resin; however, this was with a small volume of resin $(\approx 1 \mathrm{cc})$. With larger volumes of plutonium loaded resin, the ignition temperature would be much lower. The effect of volume on plutonium loaded resin was not measured, but one would predict from data obtained with unloaded resin that the ignition temperature for a $12 \mathrm{~cm}$ dia sphere of dry plutonium loaded resin would be about $100^{\circ} \mathrm{C}$. For production-scale vented ion exchange columns ( 4 in. dia), the critical ignition temperature for loaded resin would be well below $100{ }^{\circ} \mathrm{C}$.

C. Recommended Operating Practices

The following practices are recommended for reducing 
(as much as possible) the hazards involved in using nitrate form anion resins:

- Anion resin, when not in use, should be stored in some form other than the nitrate form (i.e., chloride). If the resin must be stored as the nitrate form, it should be stored in water.

- Conversion of chloride form resin to nitrate form should be accomplished with as low a normality nitric acid as is practically feasible.

- Accumulations of dry or drained nitrate form resin should be avoided at all times.

- Nitric acid concentrations in all processing operations involving anion resins should be as low as possible. - Process operating temperatures should not exceed $60{ }^{\circ} \mathrm{C}$. For further recommendations on safe operating procedures for nitric acid-anion resin systems, see the report of Van Slyke et a1.(2)

\section{REFERENCES}

1. J. Barghusen and A. A. Jonke. "Incident in Plutonium Processing Facility at Hanford," Reactor Fuel Processing, vol. 7, pp.297-404。1964。

2. W. J. Van Slyke, G. Jansen, Jr., and W. H. Swift, Thermal Effects in Anion Exchange Resin-Nitric Acid Systems, BNWL114. Battelle-Northwest, Richland, Washington, August, 1965.

3. R. H. Boundy. Styrene: Its Polymer, Copolymers, and Derivatives, Reinbold, New York. 1952.

4. J. R. Ryan. Personal Communication. Battelle-Northwest, Richland, Washington, January, 1965.

5. H. J. Borchardt and F. Daniels. "The Application of Differential Thermal Analysis to the Study of Reaction Kinetics," J. Amer. Chem.Soc., vol. 79, p. 41, 1957. 
6. N. M. Semenov. Some Problems of Chemical Kinetics and Reactivity, vol. 2, Pergamon Press. New York. 1959.

7. D. A. Frank-Kamenetskii. "Calculation of Thermal Explosion Limits," Acta Physiochimica URSS, vol. 10, pp. 365-70. 1939.

8. P. L. Chambre. "On the Solution of Poisson-Boltzmann Equations with Application to the Theory of Thermal Explosions," J. of Chem. Phys., vo1. 20, pp.1796-1797. 1952.

9. O. M. Todes, Zh. fiz, Khim, vol. 13, pp. 868, 1939. VI. ACKNOWLEDGMENT

The author desires to acknowledge the assistance received from A. O. Anderson, C.W.Hobbick, E. J. Rink, and L. A. Charlot of the Plutonium Chemistry Laboratory during the course of this work. 
RL - SEP -823

VII. APPENDIX A

A. Solutions to Thermal Balance Equations

The following solution to the thermal balance equation is taken from the work of Chambre. (8)

If one assumes the resin degradation occurs by a single reaction, the rate of heat generation within the system is given by the equation

$$
Q_{R}=f(c) \cdot H_{R} \cdot V \cdot z \cdot e^{-E / R T R}
$$

when $f(c)$ is the concentration dependence of the reaction rate. If assumed that heat loss from the system is by conduction, the thermal balance between the heat generation and heat loss is given by the equation

$$
\mathrm{k} \nabla^{2} \mathrm{~T}_{\mathrm{R}}=\mathrm{f}(\mathrm{c}) \cdot \mathrm{H}_{\mathrm{R}} \cdot \mathrm{V} \cdot \mathrm{z} \cdot \mathrm{e}^{-\mathrm{E} / \mathrm{RT}} \mathrm{R} \text {. }
$$

By applying certain boundary conditions, Equation A-2 can be solved for various resin system geometries. The values of the parameters at which a solution becomes impossible is taken as the critical wall temperature and resin ignition temperature for the particular system geometry.

It has been shown by Todes ${ }^{(9)}$ that the maximum temperature difference $\left(T_{R}-T_{W}\right)$ before the thermal explosion occurs is approximately $\frac{\mathrm{RT}_{W}}{\mathrm{E}}$. If the exponent in the term $e^{-E / R T_{R}}$ is expanded in a series of $\frac{T_{R}-T_{W}}{T_{W}}$ and all powers except the first neglected, we get

$$
\begin{aligned}
& -\frac{E}{\mathrm{RT}_{\mathrm{R}}} \cong-\frac{E}{\mathrm{RT}_{W}}\left[1-\frac{\mathrm{T}_{\mathrm{R}}-\mathrm{T}_{W}}{\mathrm{~T}_{W}}\right] . \\
& \text { Letting } \theta=\frac{E}{R T_{W}{ }^{2}}\left(\mathrm{~T}_{\mathrm{R}}-\mathrm{T}_{W}\right),
\end{aligned}
$$


Equation A-2 becomes

$$
\nabla^{2} \theta=-\left[\frac{H_{R}}{k} \frac{E}{R T_{W}^{2}} \cdot f(c) \cdot z \cdot e^{-E / R T_{W}}\right] e^{\theta} .
$$

If the reaction is assumed to be unimolecular, and the system space coordinate $x$ is replaced with the dimensionless unit $N$ where $N=\frac{x}{r}$ ( $r$ is the significant dimension of the system), the Poisson Boltzmann equation is obtained

$$
\frac{d^{2} \theta}{d N^{2}}+\frac{L d \theta}{N d n}=-\delta e^{\theta}
$$

where $\delta=\left[\frac{{ }_{R}}{k} \cdot \frac{E}{R_{T} T^{2}} \cdot r^{2} \cdot c \cdot z \cdot e^{-E / R T_{W}}\right]$.

Chambre ${ }^{(8)}$ has solved Equation A-5 for both a cylindrical vessel and a spherical vessel, and his solutions are given. below [For a cylinder with the following boundary conditions $(L=1)]$ :

At the center of the vessel

$N=0 ; \frac{d \theta}{d N}=0$;

at the walls

$$
N=1 ; \theta=0 \text {. }
$$

Introducing the variables

$$
n=N^{2} e^{\theta}, \omega=N \frac{d \theta}{d N}
$$

Equation A-5 becomes

$$
\frac{d \omega}{d n}=-\delta /(2+\omega) \text {. }
$$

The general integral is

$$
\omega^{2}+4 \omega+D=-2 \delta n \text {. }
$$


Owing to the boundary condition at the center

$$
D=0 \text {. }
$$

Therefore,

$$
N^{2}\left(\frac{d \theta}{d N}\right)^{2}+4 N \frac{d \theta}{d N}=-2 \cdot \delta \cdot N^{2} \cdot e^{\theta}
$$

however, from Equation A-5,

$$
2 N^{2}\left(\frac{d^{2} \theta}{d N^{2}}\right)+2 N \frac{d \theta}{d N}=-2 \cdot \delta \cdot N^{2} \cdot e^{\theta} .
$$

Eliminating the common terms, we get

$$
\frac{\mathrm{d}^{2} \theta}{\mathrm{dN}^{2}}-\frac{1}{\mathrm{~N}} \frac{\mathrm{d} \theta}{\mathrm{dN}}-1 / 2\left(\frac{\mathrm{d} \theta}{\mathrm{dN}}\right)^{2}=0 .
$$

The solution of this equation is

$$
\theta=A-2 \ln \left(B N^{2}+1\right) \text {. }
$$

From Equations $\mathrm{A}-13$ and $\mathrm{A}-5$

$$
A=\ln \left(\frac{8 B}{\delta}\right)
$$

so that

$$
\theta=\ln \left[\frac{8 \mathrm{~B} / \delta}{\left(\mathrm{BN}^{2}+1\right)^{2}}\right] \text {. }
$$

Since at the vessel wall, $N=1$ and $\theta=0$,

$$
\frac{8 B / \delta}{(B+1)^{2}}=1
$$

The maximum value of $\delta$ for which a solution is possible is

$$
\delta_{\text {crit }}=2, B=1 \text {; }
$$

therefore,

$$
{ }_{\text {crit }}=\ln \left[\frac{4}{\left(N^{2}+1\right)^{2}}\right] \text {. }
$$


The maximum dimensionless temperature is

$$
{ }^{\theta} \max \text {. } \operatorname{crit}=1 \mathrm{n} 4 \text {. }
$$

Similar equations can be obtained for spherical geometry and the results are

$$
\begin{aligned}
& \delta_{\text {crit }}=3.32 ; \\
& \theta_{\max \cdot \operatorname{crit}}=1.61 .
\end{aligned}
$$

VIII. APPENDIX B - NOMENCLATURE

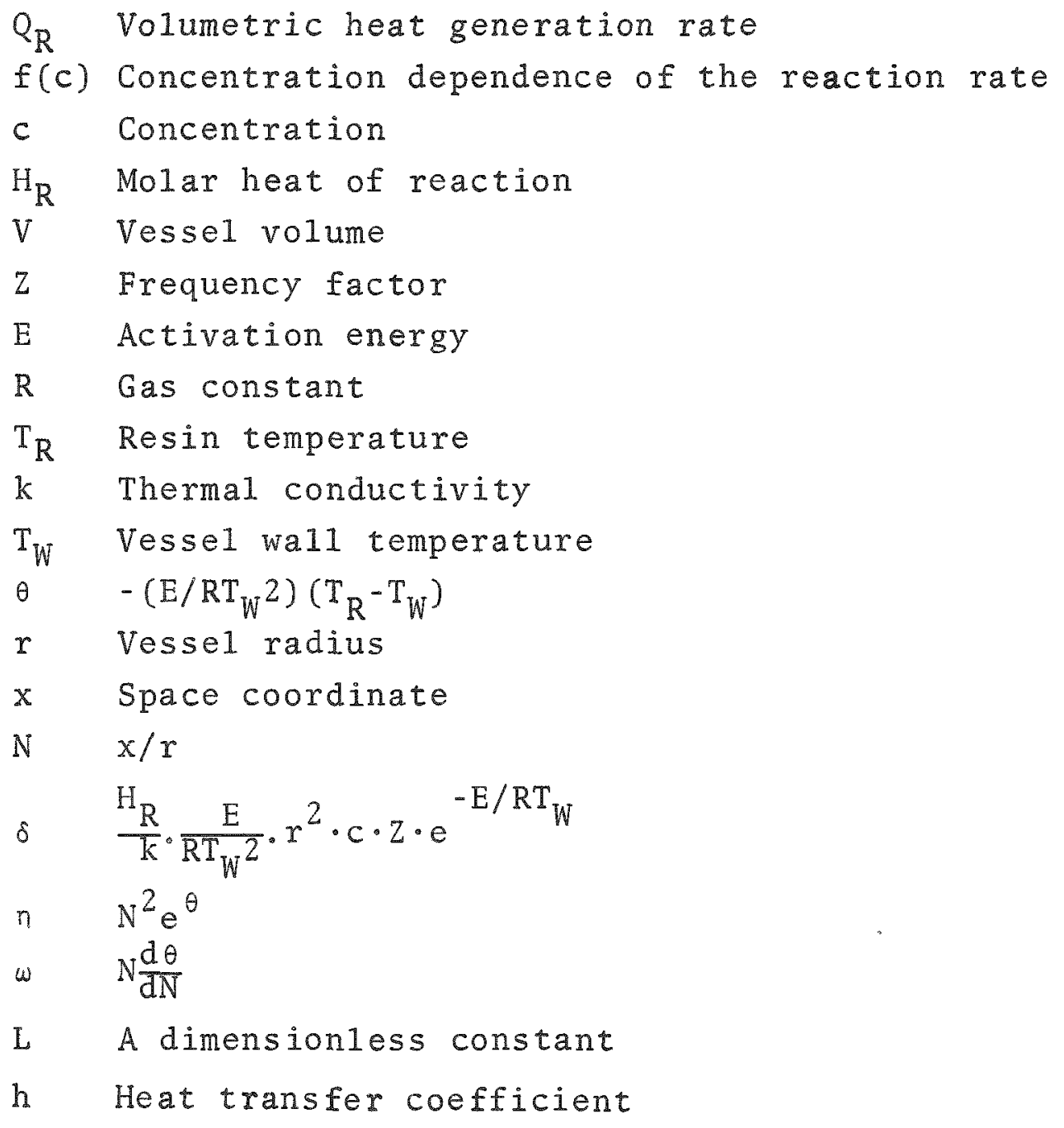




\section{DISTRIBUTION}

Copy Number

$1-19$

BATTELLE-NORTHWEST

G. Jansen, Jr.

H. T. Fuliam(10)

F. P. Roberts

J. L。 Ryan

W. H. Swift

W. J. Van Slyke

E. E. Voiland

E.J.Wheelwright

Technical Publications

$19-351$

DIVISION OF TECHNICAL INFORMATION EXTENSION

$352-355$

DOW CHEMICAL COMPANY

Rocky Flats Division

J。T B Byrne

G. Molen(2)

A. Williams

DU PONT COMPANY, AIKEN

Savannah River Laboratory

C. H. Ice

$357-412$

ISOCHEM INC 。

S. J. Beard

M. H. Campbel1

M. H. Curtis

R. E. Felt

O. F. Hill

$\mathrm{H}$. H. Hopkins, Jr。(10)

$\mathrm{H}$ 。 A Rathvon

P. E. Reed

M. J.Szulinski

R. E. Tomlinson

Isochem File Copy

General Electric File Copy

Extra(35)

$413-415$

RICHLAND OPERATIONS OFFICE

A. T. Parker

$R$ 。 $K$ 。 Sharp

Technical Information Library 